UII norden

Kartläggning av matsvinnet i primärproduktionen

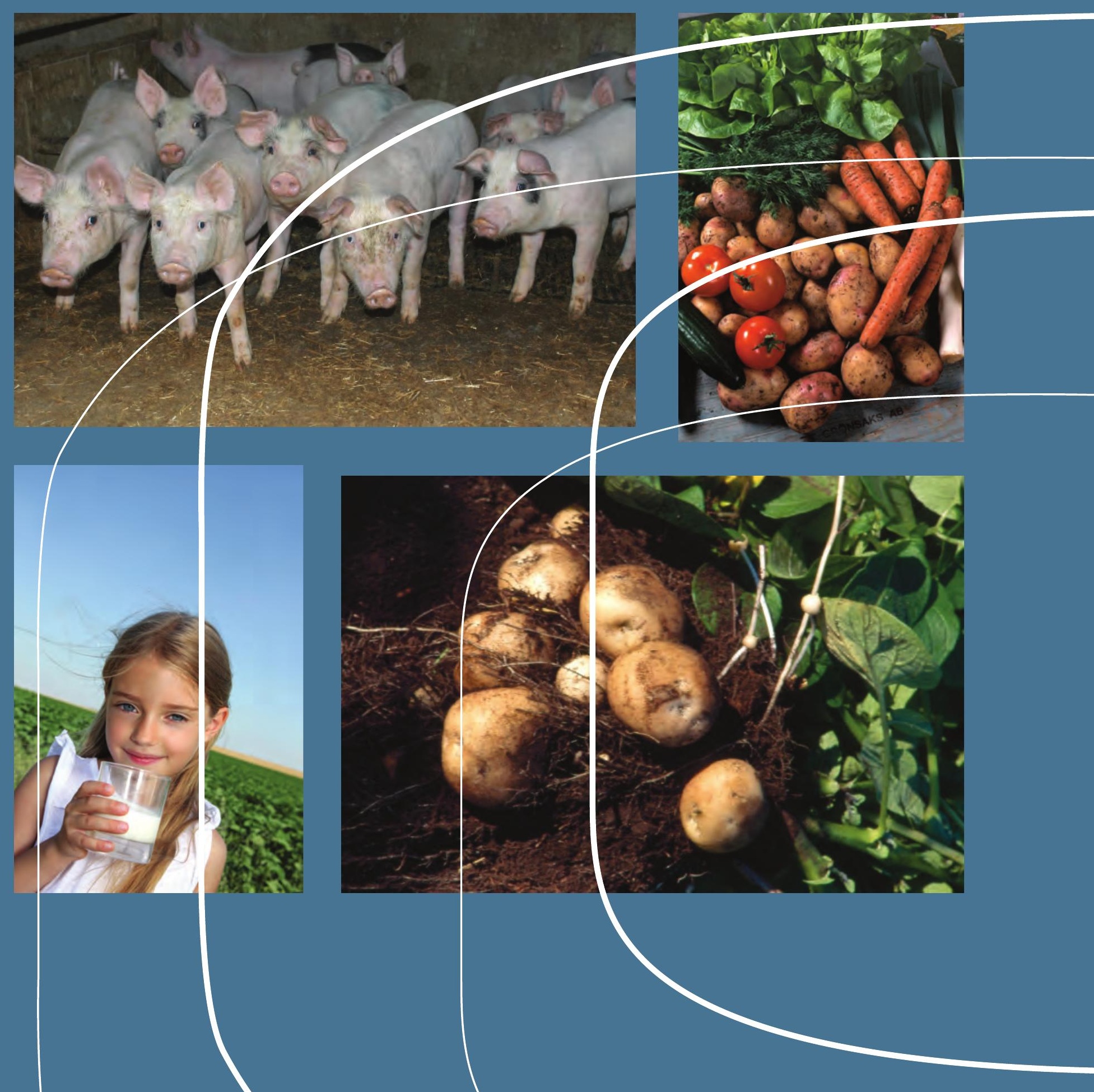



4 norden 



\section{Kartläggning av matsvinnet i primärproduktionen}

Ulrika Franke, Elin Einarson, Niels Andrésen, Erik Svanes,

Hanna Hartikainen och Lisbeth Mogensen

TemaNord 2013:581 
Kartläggning av matsvinnet i primärproduktionen

Ulrika Franke, Elin Einarson, Niels Andrésen, Erik Svanes, Hanna Hartikainen och Lisbeth Mogensen

ISBN 978-92-893-2649-0

http://dx.doi.org/10.6027/TN2013-581

TemaNord 2013:581

(c) Nordiska ministerrådet 2013

Layout: Hanne Lebech

Omslagsfoto: ̈verst t.h.: Ulf Nylén; överst t.h.: Per G Norén;

nederst t.v.: shutterstock; nedst t.h.: Uffe Andersson

Foto: s. 68: Per G. Norén

Denna rapport är utgiven med finansiellt stöd från Nordiska ministerrådet. Innehållet i rapporten avspeglar inte nödvändigtvis Nordiska ministerrådets synpunkter, åsikter eller rekommendationer.

www.norden.org/sv/publikationer

\section{Det nordiska samarbetet}

Det nordiska samarbetet är ett av världens mest omfattande regionala samarbeten. Det omfattar Danmark, Finland, Island, Norge och Sverige samt Färöarna, Grönland och Åland.

Det nordiska samarbetet är politiskt, ekonomiskt och kulturellt förankrat och är en viktig partner i europeiskt och internationellt samarbete. Den nordiska gemenskapen arbetar för ett starkt Norden i ett starkt Europa.

Det nordiska samarbetet ska stärka nordiska och regionala intressen och värderingar i en global omvärld. Gemensamma värderingar länderna emellan bidrar till att stärka Nordens ställning som en av världens mest innovativa och konkurrenskraftiga regioner.

Nordiska ministerrådet

Ved Stranden 18

DK-1061 København K

Telefon (+45) 33960200

\section{www.norden.org}




\section{Innehåll}

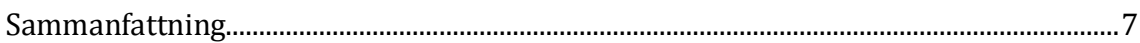

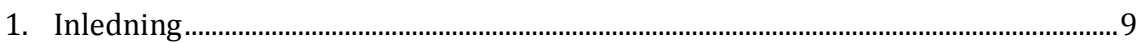

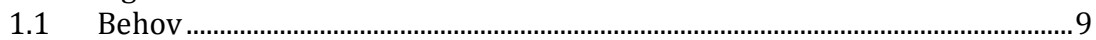

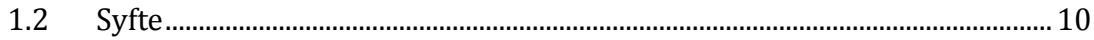

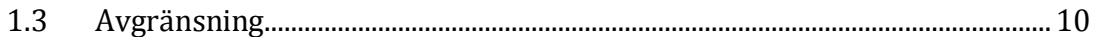

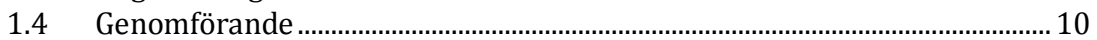

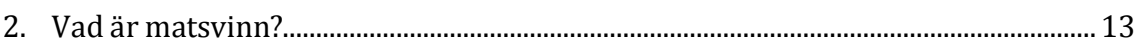

2.1 Definition och avgränsning ................................................................................ 13

2.2 Definitioner och avgränsningar enligt FAO ...................................................... 15

3. Vad vet vi idag? ............................................................................................................. 17

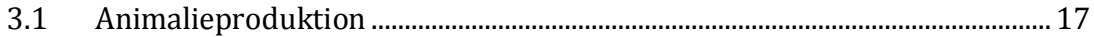

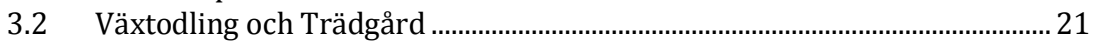

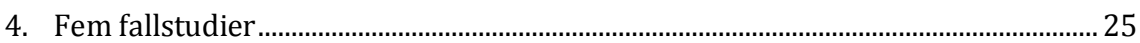

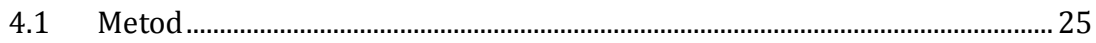

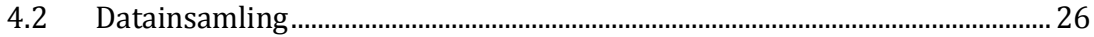

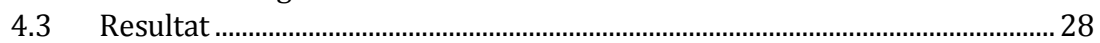

4.4 Diskussion av fallstudierna......................................................................... 34

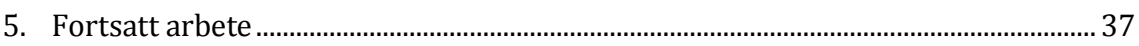

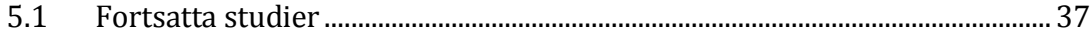

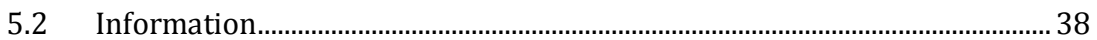

5.3 Innovation ....................................................................................................... 39

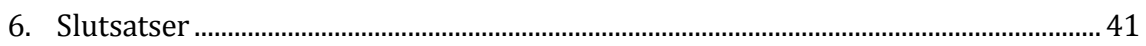

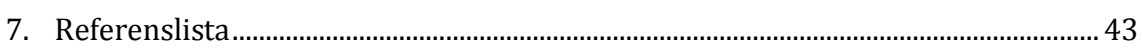

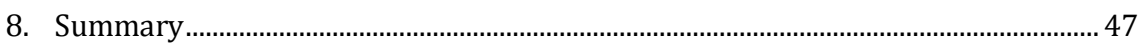


9. Appendix Norway "food waste" in the primary production of carrots and

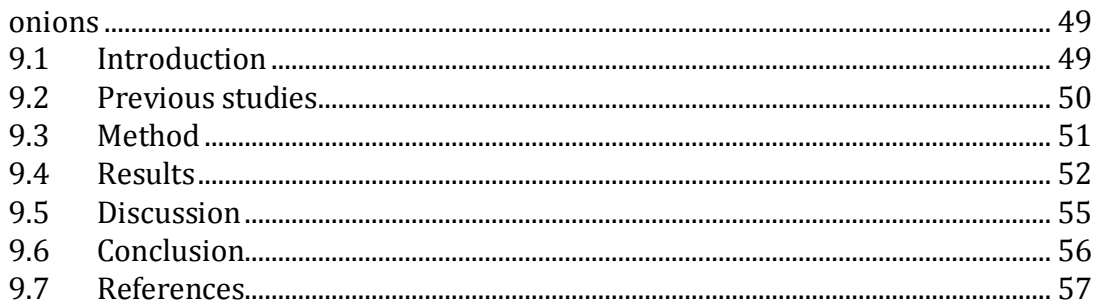

10. Appendix Finland "food waste" during primary production of potato .................... 59

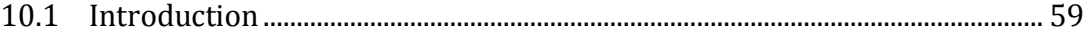

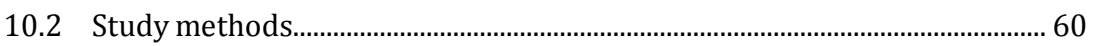

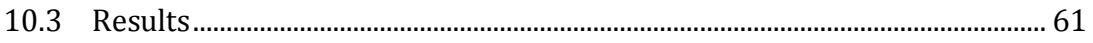

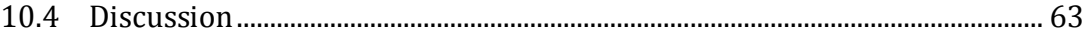

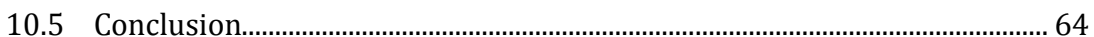

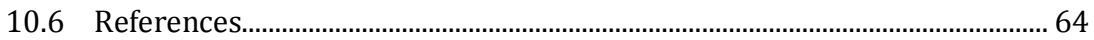

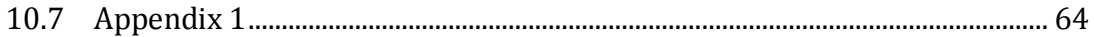

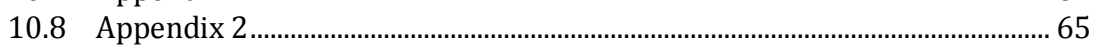

11. Appendix Sweden "food waste" in primary production of milk.................................67 67

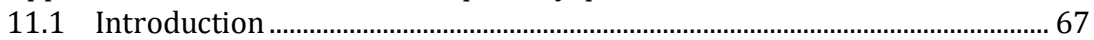

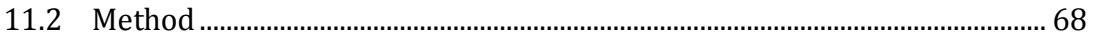

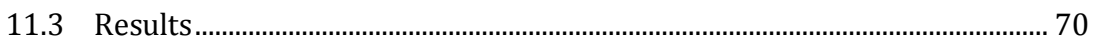

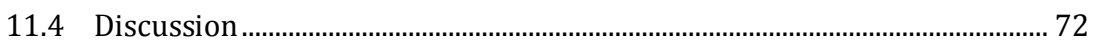

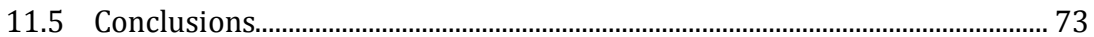

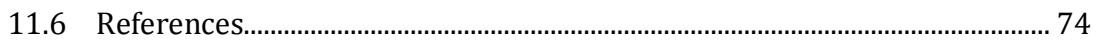

12. Appendix Denmark "food waste" in primary production of pork............................. 75

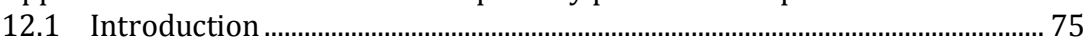

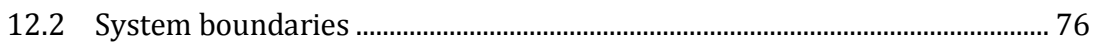

12.3 Choice of method

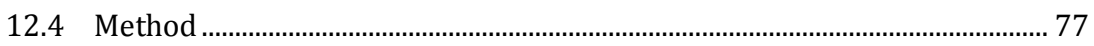

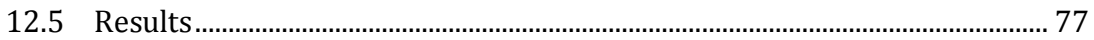

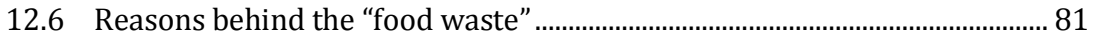

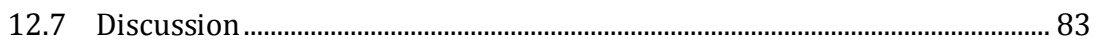

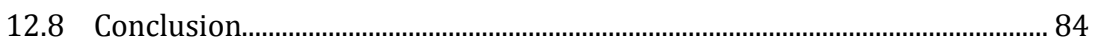

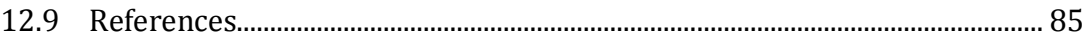




\section{Sammanfattning}

Mat slängs i alla delar av livsmedelskedjan, från produktion till konsument. Statistik och data finns för flera av leden i kedjan, men för primärproduktionen saknas tillförlitliga data på hur stort svinnet är.

Vi skiljer mellan vad som är produktionsförluster och matsvinn inom primärproduktionen, men har i den här studien valt att använda oss av begreppet svinn som innefattar båda delarna.

Vi har gjort en litteraturstudie för att få en bild av hur stort svinnet kan tänkas vara för olika produktgrupper och vad det kan tänkas bero på. Det varierar mycket mellan de olika produktgrupperna, men kvalitetskrav från konsumenterna lyfts fram som en viktig orsak till svinn av även i primärproduktionsledet, framför allt för produktion av frukt och grönsaker.

Inom projektet har vi gjort en datainsamling för fem produkter och för dem studerat svinnet på en mer detaljerad nivå. De fem produkterna är morot, potatis, lök, mjölk och griskött. Av studien framgår att det är stora mängder råvara som hade kunnat bli mat, men som blir till förluster eller svinn i primärproduktionen. Detta har konsekvenser för producenternas ekonomi, mängden tillgänglig odlingsmark och klimatet. Den negativa påverkan är större för mjölk och griskött även om andelen svinn är högre för morötter, lök och potatis.

Det finns ett behov av fortsatta studier för att få en bättre bild av svinnet inom primärproduktionen. För att minska svinnet behövs bättre genomlysning av vad som gör att svinnet uppstår, hur normer och kvalitetskrav påverkar svinnet och vad vi kan göra för att minska det. Producenterna kan också behöva ytterligare kunskap om svinnet och vad de kan göra för att minska det. En stimulering till ett ökat utnyttjande av hela produkten är något som också kan leda till att minska svinnet.

Det finns potential till att minska svinnet i primärproduktionen, men det är omöjligt att reduceras det till noll. Så ett visst svinn får vi räkna med även i framtiden. 



\section{Inledning}

Mellan 30 och 50 procent av maten som produceras i världen blir inte mat trots att syftet är att den ska ätas (Fox, 2013 och FAO, 2011). Orsakerna till detta varierar mellan länder, mellan produktslag och mellan de olika leden i livsmedelskedjan. Samtidigt behövs troligen en viss överproduktion, för att marknaderna globalt ska fungera och för att inte bristsituationer ska uppstå.

I de båda studierna anges viktiga orsaker till att maten som produceras inte äts. I utvecklingsländerna är svinnet störst i första delen av livsmedelskedjan och beror t.ex. på ineffektiva jordbruksmetoder, brister i infrastruktur och att maten lagras på fel sätt. I den utvecklade delen av världen är det svinnet i konsumentledet som är det stora problemet. Men även orsaker som regelverk kopplade till smittskydd, djurhållning eller olika stödsystem tas upp. En annan orsak som lyfts fram är kvalitetskraven och en accelererande önskan eller strävan mot homogena produkter.

Genom att minska svinnet kan resurserna som behövs för att producera mat användas på ett klokare sätt och i optimala fall kan fler munnar mättas. Dessutom kan mängden avfall minskas avsevärt.

\subsection{Behov}

Titt som tätt efterfrågas data på avfallsmängder eller svinn i primärproduktionen och det har varit svårt att hitta tillförlitlig data på detta. Naturvårdsverket i Sverige har låtit Svenska MiljöemissionData (SMED) ta fram statistik för matavfall i Sverige. Målet med studien var att ta fram förbättrade data över matavfall i hela livsmedelskedjan och statistiken ska användas till att följa upp Sveriges avfallsmål. I studien konstateras att det saknas tillförlitliga data på avfallsflödet i primärproduktionen i Sverige (Jensen, Stenmarck, Sörme, \& Dunsö, 2011). Vi har sett ett behov att ta fram statistik för svinn inom primärproduktionen.

\subsubsection{Mål för minskat matsvinn}

Europaparlamentets har antagit en resolution att man ska minska matsvinnet med 50 procent år 2025 med utgångspunkt 2010 (Europaparlamentet 2012).

Naturvårdsverket har tagit fram en rapport som underlag till ett nytt nationellt mål att minska matavfallet. I rapporten beskrivs vilken 
ekonomisk nytta en minskning av matsvinnet skulle innebära. (Kock \& Andersson, 2012)

\subsection{Syfte}

Syftet med denna studie är att definiera vad som är matsvinn i primärproduktionen och i möjligaste mån kvantifiera hur stort svinnet är för några utvalda produktgrupper.

\subsection{Avgränsning}

Den här studien är avgränsad till kartläggning av matsvinn och produktionsförluster i primärproduktionen. En mer utförlig avgränsning av vad detta innebär beskrivs i kapitel 2.

\subsection{Genomförande}

Uppdraget har letts och genomförts som ett projekt vid Jordbruksverket med styrgrupp och referensgrupp från Jordbruksverket. Arbetet har utförts av en arbetsgrupp bestående av representanter från Norge, Finland, Danmark och Sverige.

Projektet har bestått av fyra olika delar:

1. En sammanställning av vad som kan klassas som svinn inom primärproduktionen och orsaker till svinnet i Sverige. Denna sammanställning har gjorts med hjälp av en referensgrupp från Jordbruksverket.

2. En litteraturstudie om svinn inom primärproduktionen. Denna del innehåller en sammanställning av framtagen data på svinn inom primärproduktionen som har gått att hitta i litteratur eller statistiksammanställningar.

3. En datainsamling på nordisk nivå har gjorts av svinnet för fem vanliga produktgrupper; potatis, morötter, lök, mjölk och griskött. Vi har även anordnat en workshop för att föra ut resultatet av kartläggningen till berörda organisationer och diskutera behov av fortsatt arbete.

4. En analysdel med rekommendationer till fortsatt arbete. För denna del har vi tagit hjälp av referensgruppen, litteraturstudien, datainsamlingen och workshopen. 


\section{Arbetsgruppen har bestått av}

Ulrika Franke (projektledare), Elin Einarson och Daniel Persson, Jordbruksverket, Erik Svanes, Østfoldforskning, Hanna Hartikainen, MTT, Lisbeth Mogensen, Aarhus Universitet och Martin Fischer, Natur Erhvervstyrelsen.

\section{Styrgruppen på Jordbruksverket har letts av}

Martin Sjödahl. Anette Kjellberg, Kristina Mattsson och Helena Kättström har varit ledamöter.

I referensgruppen har Niels Andersén, Johan Ascard, Christina Winter, Katarina Holstmark, Marianne Sköld, Daniel Melin, Håkan Loxbo och Katarina Johansson från Jordbruksverket deltagit. 



\section{Vad är matsvinn?}

\subsection{Definition och avgränsning}

Med matsvinn menar vi i den här studien:

"Mat som framställs i syfte att ätas av människor, men som av olika anledningar inte äts."

Med mat menar vi i den här studien:

"Alla ämnen eller produkter, oberoende av om de är bearbetade, delvis bearbetade eller obearbetade, som är avsedda att eller rimligen kan förväntas att förtäras av människor." (Definition av livsmedel enligt EG 178/2002).

Enligt samma förordning inbegriper inte mat: foder, växter före skörd eller levande djur, utom om de har behandlats för att släppas ut på marknaden som livsmedel. Matsvinn i primärproduktionen omfattar därmed växter eller växtdelar efter skörd och animaliska produkter efter slakt eller fångst. Vissa skaldjur såsom hummer som säljs levande betraktas som livsmedel i detta sammanhang.

Med primärproduktion menar vi i detta sammanhang produktion av jordbruks- och trädgårdsprodukter, fiske och vattenbruk. Det innebär att vi inte inkluderar jakt, bärplockning och hobbyodling. Vi har i första hand valt att fokusera på vanliga produkter med stora produktionsvolymer.

I primärproduktionen finns både matsvinn och produktionsförluster, (tabell 1). I den senare kategorin ingår t.ex. förluster p.g.a. växtskadegörare, djursjukdomar andra dödsorsaker bland husdjur. I denna studie inkluderar vi både matsvinn och produktionsförluster för att få en helhetsbild av primärproduktionen. Vi har valt att använda samlingsbegreppet svinn för båda företeelserna i rapporten, då det inte finns något vedertaget begrepp att använda sedan tidigare.

Vi tar inte hänsyn till ineffektiv produktion eller träda i denna kartläggning. Inte heller till att mark används till produktion av foder i stället för produktion av mat till människor. Vi räknar heller inte med faktorer som har betydelse för hur mycket livsmedel som kan produceras, såsom markstruktur, gödsling eller fodertillgång. Orsaken till denna avgränsning är att studera den faktiska produktionen isolerad från andra processer. 
Fokus ligger på de förluster och det matsvinn som uppstår innan industri, handel och konsumentled. I vår definition av svinn ingår både sådant som blir avfall och sådant som t.ex. går till djurfoder i stället för mat. I senare led i kedjan definieras matsvinn som en del av livsmedelsavfallet. Den avgränsningen fyller inte vårt syfte när det gäller primärproduktionen. Om vi skulle använda samma avgränsning, skulle troligtvis endast den lilla del som går till slutlig avfallshantering räknas som svinn. Frågan angrips alltså här ur ett produktionsperspektiv och inte ur ett avfallsperspektiv. Detta betyder dock inte att allt som inte blir svinn verkligen går till humankonsumtion. Exempel på detta är kan vara ben från kött eller skal från lök.

Svinn beräknas i studien som procent svinn av den totala produktionen:

$$
\text { Andel svinn i primärproduktionen }=\frac{\text { Totalt svinn }}{\text { Total produktion }}
$$

Total produktion är den totala produktionsmängden inklusive det som inte går vidare till humankonsumtion.

Tabell 1: Definition och avgränsning av matsvinn i primärproduktionen, i förhållande till produktionsförluster i primärproduktionen

\begin{tabular}{|c|c|c|}
\hline \multirow[t]{2}{*}{ Produktgrupp } & \multicolumn{2}{|c|}{ Svinn i primärproduktionen } \\
\hline & $\begin{array}{l}\text { Produktionsförluster i primärproduktionen } \\
\text { Exempel: }\end{array}$ & $\begin{array}{l}\text { Matsvinn i primärproduktionen } \\
\text { Exempel: }\end{array}$ \\
\hline Kött, jordbruk & $\begin{array}{l}\text { Minskad tillväxt p.g.a. djursjukdomar; in- } \\
\text { optimal utfodring; smågrisdödlighet }\end{array}$ & $\begin{array}{l}\text { Från slakt till lastning för transport från } \\
\text { gård, alternativt gårdsförsäljning }\end{array}$ \\
\hline Mjölk & $\begin{array}{l}\text { Minskad produktion p.g.a. djursjukdomar; } \\
\text { inoptimal utfodring }\end{array}$ & $\begin{array}{l}\text { Efter mjölkning fram till lastning på } \\
\text { mjölkbil }\end{array}$ \\
\hline Ägg & $\begin{array}{l}\text { Minskad produktion p.g.a. djursjukdomar; } \\
\text { inoptimal utfodring }\end{array}$ & Från plockning till lastning för utleverans \\
\hline Renskötsel & $\begin{array}{l}\text { Minskad produktion p.g.a. djursjukdomar } \\
\text { eller rovdjursangrepp; inoptimal utfodring }\end{array}$ & $\begin{array}{l}\text { Slakt egenregi; Från slakt till lastning } \\
\text { för transport. Annan slakt: fram till } \\
\text { lastning för transport till slakteri }\end{array}$ \\
\hline Fiske & & $\begin{array}{l}\text { Från fångst som tagits ombord till att } \\
\text { leverans är lastad }\end{array}$ \\
\hline Vattenbruk & $\begin{array}{l}\text { Minskad produktion p.g.a. sjukdomar; in- } \\
\text { optimal utfodring; }\end{array}$ & Från skörd till att leverans är lastad \\
\hline $\begin{array}{l}\text { Växtodling och } \\
\text { trädgård }\end{array}$ & $\begin{array}{l}\text { Lägre avkastning p.g.a. växtskadegörare, } \\
\text { inoptimal gödsling, ineffektiv jordbearbet- } \\
\text { ning }\end{array}$ & $\begin{array}{l}\text { Från skörd till lastning för transport } \\
\text { från gård }\end{array}$ \\
\hline
\end{tabular}




\subsection{Definitioner och avgränsningar enligt FAO}

FAO har låtit undersöka livsmedelsförluster och livsmedelssvinn globalt och delar upp dem på följande sätt (FAO, 2011):

\section{Livsmedelsförluster}

Livsmedelsförluster definieras som minskad kvantitet eller kvalitet och uppkommer framförallt tidigt i livsmedelskedjan, men kan även förekomma senare i kedjan. Förluster är oavsiktliga och beror på strukturella problem, såsom avsaknad av infrastruktur, bristande kylkedja eller bristfälliga förpackningar.

\section{Livsmedelssvinn}

Livemedelssvinn är produkter som är redo att konsumeras eller att gå vidare i livsmedelskedjan, men som kastas. Det uppstår oftast i senare delen av livsmedelskedjan, såsom butiker eller hushåll. Matsvinn är avsiktligt - genom ett aktivt val sorteras något bort som är tjänligt. Orsaken till sorteringen kan dock ha sin grund i ett strukturellt problem.

I FAO-rapporten uppskattas livsmedelsförlusterna och livsmedelssvinnet i olika delar av livsmedelskedjan enligt följande uppdelning:

Figur 1. Livsmedelskedjan så som den är definierad enligt FAO (FAO, 2011)

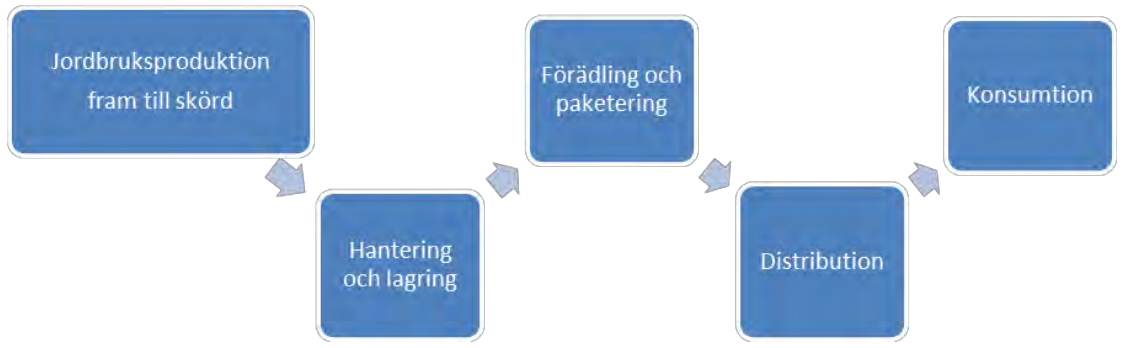





\section{Vad vet vi idag?}

I detta kapitel har vi gått igenom litteratur och inhämtat kunskap från projektets referensgrupp och andra specialister för att kartlägga storleksordning och orsaker till svinn, både i form av matsvinn och i form av en produktionsförlust. I många fall går det inte att urskilja om det är en förlust eller om det är ett matsvinn och i de fallen väljer vi att använda ordet svinn som en beteckning för både förluster och matsvinn (se kap 2).

\subsection{Animalieproduktion}

Svinn i animalieproduktionen uppstår när djur dör vid födsel, i uppfödning och i transporter till slakteri. Avlivning av djur, då köttet inte kan tas om hand, innebär också ett svinn. Detta kan ske till exempel vid akuta skador eller då djuret måste avlivas under pågående eller nyligen avslutad antibiotikabehandling. Det finns också beteenden i senare led i värdekedjan som bidrar till svinn inom animalieproduktionen. Dessa beteenden är framförallt kopplade till efterfrågan av olika produkter. Det finns t.ex. i dagsläget störst efterfrågan på "vanlig" matfisk som lax, sej och torsk men för att fånga dessa fiskar får man också bifångster av så kallade lågvärdefisk. Dessa skulle kunna bli mat åt människor om det funnits en efterfrågan på dem. Ett annat exempel är att vissa delar av djur såsom klövar och öron från grisar inte äts i någon större omfattning trots att det vore möjligt. Möjligheter finns dock att ta tillvara på fisk och delar av djur som inte äts genom tillverkning av t.ex. fiskbullar eller korv.

\subsubsection{Kött}

Tabell 2 visar uppgifter från litteratur där svinn i produktionen är kartlagd i procentuell andel av den totala produktionen. I vissa fall har olika källor kommit fram till olika resultat. Detaljer om detta hittas under kolumnen "Förklaring och källa." 
Tabell 2: Svinn inom olika produktionsgrenar: nötkreatur, gris, får, kyckling och kalkon

\begin{tabular}{|c|c|c|c|}
\hline Produkt & Typ av svinn & Andel svinn & Förklaring och källa \\
\hline \multicolumn{4}{|c|}{ Nötkreatur } \\
\hline & $\begin{array}{l}\text { Produktionsförlust i } \\
\text { form av dödlighet i } \\
\text { uppfödning }\end{array}$ & $4-8,5 \%$ & $\begin{array}{l}\text { Svensk uppfödning av nöt köttdjur. Statistik från databasen } \\
\text { KAP (Kött Avel Produktion) visar siffror mellan 5,5\% och 8,5 } \\
\text { beroende på om det är en ko (5,5 \%) eller kviga ( } 8,5 \% \text { ) som } \\
\text { är modern. Av de kalvar som dör så dör de flesta vid för- } \\
\text { lossningen (Stenberg H., 2010). Jordbruksverkets statistik } \\
\text { visar att andelen dödfödda kalvar år } 2008 \text { var mellan } 4 \text { och } \\
8 \% \text { och att andelen var lägre om kalvarna var födda på ett } \\
\text { mjölkkoföretag (4 \%) än om de var födda på ett köttkoföre- } \\
\text { tag (Jordbruksverket, 2012). Andelen dödfödda är ungefär } \\
\text { lika hög i amerikansk uppfödning av mjölkkor (McConnel, } \\
\text { Lombard, Wagner, \& Garry, 2008) }\end{array}$ \\
\hline & $\begin{array}{l}\text { Svinn i form av trans- } \\
\text { portdödlighet nötkrea- } \\
\text { tur }\end{array}$ & $0,013 \%$ & $\begin{array}{l}\text { Viktat medelvärde från (Gustavsson, Cederberg, Sonesson, } \\
\text { \& Emanuelsson, 2013) baserat på studier på gris och } \\
\text { nötkreatur (Malena \& Voslarova, 2007) }\end{array}$ \\
\hline \multicolumn{4}{|l|}{ Gris } \\
\hline & $\begin{array}{l}\text { Produktionsförlust i } \\
\text { form av dödlighet i } \\
\text { uppfödning }\end{array}$ & $2,5 \%$ & $\begin{array}{l}\text { Svensk grisuppfödning enligt uppgift hittad på Svenska pigs } \\
\text { hemsida } 2010 \text { enligt (Gustavsson, Cederberg, Sonesson, \& } \\
\text { Emanuelsson, 2013). }\end{array}$ \\
\hline & $\begin{array}{l}\text { Svinn i form av trans- } \\
\text { portdödlighet gris }\end{array}$ & 0,11 & $\begin{array}{l}\text { Viktat medelvärde från (Gustavsson, Cederberg, Sonesson, } \\
\text { \& Emanuelsson, 2013) baserat på studier på gris och } \\
\text { nötkreatur (Malena \& Voslarova, 2007) }\end{array}$ \\
\hline \multicolumn{4}{|l|}{ Får } \\
\hline & $\begin{array}{l}\text { Produktionsförlust } \mathrm{i} \\
\text { form av dödlighet i } \\
\text { uppfödning }\end{array}$ & $\begin{array}{l}\text { Lamm: 4-19 \% } \\
\text { Făr: 3-4 \% }\end{array}$ & $\begin{array}{l}\text { Svensk uppfödning av får och lamm, data använt för livscy- } \\
\text { kelanalys (Wallman, Cederberg, \& Sonesson, 2011) }\end{array}$ \\
\hline & $\begin{array}{l}\text { Svinn i form av trans- } \\
\text { portdödlighet }\end{array}$ & $0,018 \%$ & $\begin{array}{l}\text { Viktat medelvärde från (Gustavsson, Cederberg, Sonesson, } \\
\text { \& Emanuelsson, 2013) baserat på studier av transport av får } \\
\text { (Knowels, 1998) }\end{array}$ \\
\hline \multicolumn{4}{|l|}{ Kyckling } \\
\hline & $\begin{array}{l}\text { Produktionsförlust i } \\
\text { form av dödlighet i } \\
\text { stallarna }\end{array}$ & $3-3,5 \%$ & $\begin{array}{l}\text { Svensk kycklinguppfödning. Den högre siffran baseras sig på } \\
\text { uppgifter från Kronfågel } 2008 \text { om dödlighet i uppfödning } \\
\text { (Cederberg, Sonesson, Henriksson, Davis, \& V, 2009). Maria } \\
\text { Donis, VD Svensk Fågel anger i samtal hösten } 2012 \text { att } \\
\text { dödligheten ligger ungefär runt } 3 \text { \% (Donis Maria e-post, } \\
\text { 2012). }\end{array}$ \\
\hline & $\begin{array}{l}\text { Svinn i form av trans- } \\
\text { port till slakteri }\end{array}$ & $0,15-1,5 \%$ & $\begin{array}{l}\text { Transportdödlighet enligt (Sällvik, Palmén, Bäcklund, \& } \\
\text { Bostad, 2007). Maria Donis, VD för Svensk Fågel har i ett } \\
\text { samtal hösten } 2012 \text { berättat att genomsnittlig dödlighet för } \\
\text { svenska transporter är 0,2 \% (Donis Maria e-post, 2012). } \\
\text { Livsmedelsverkets statistik visar att 0,2 \% av alla kycklingar } \\
\text { som anländer till slakteriet är självdöda (Gåle Gunilla e-post, } \\
\text { 2012). }\end{array}$ \\
\hline & $\begin{array}{l}\text { Svinn i form av kasse- } \\
\text { ring på slakteriet }\end{array}$ & $1-2 \%$ & $\begin{array}{l}\text { Kasserade svenska kycklingar vid slakteri, statistik mellan } \\
2005 \text { och } 2011 \text { (Jordbruksverkets statistikdatabas, 2012) }\end{array}$ \\
\hline \multicolumn{4}{|l|}{ Kalkon } \\
\hline & $\begin{array}{l}\text { Produktionsförlust i } \\
\text { form av dödlighet i } \\
\text { kalkonuppfödning }\end{array}$ & $8 \%$ & $\begin{array}{l}\text { Svensk uppfödning av kalkon, data använt för livscykelana- } \\
\text { lys (Wallman \& Sonesson, Life Cycle Assessment (LCA) of } \\
\text { Swedish production of Turkey, 2009) }\end{array}$ \\
\hline
\end{tabular}




\section{Nötkreatur}

Dödlighet bland kalvar är framförallt förknippad med förlossningen. Hull inhysningssystem och avelsurval av dikor är viktiga faktorer för att minska kalvdödligheten (Höglund, 2010). Tjurkalvar från vissa mjölkraser med låg tillväxt och köttansättning, t.ex. Holstein i Sverige eller Jerseykor i Danmark, är svåra att föda upp i köttproduktionen och samtidig få en lönsam produktion. Det innebär att kalvar avlivas direkt vid födsel i vissa fall. Detta är även ett etiskt dilemma att friska djur inte kan utnyttjas i produktionen. Med könssorterad sperma går det att styra produktionen mot fler kvigkalvar av mjölkras och flera tjurkalvar med köttraskorsning. På detta sätt ökar man tillväxten och köttansättningen på tjurkalvarna från mjölkproduktionen, vilket är viktigt för lönsamheten (Andresen Nils muntligen, 2012).

\section{Gris}

Största anledningen till bortfall inom grisuppfödning är att smågrisdödligheten är hög. Fixerade suggor skulle kunna innebära lägre smågrisdödlighet, men detta ska vägas mot djurskyddet. Smågrisdödligheten har minskat på senare år i Sverige, vilket bland annat beror på bättre miljö i djurstallar och mer gruppvis uppfödning. Detta gör det lättare att rengöra och städa mellan djurgrupperna. Gris är en av de fem produktgrupper som har studerats i fallstudierna. Resultatet redovisas i kapitel 4.

\section{Får, lamm och getter}

Får och getter avlivas ofta istället för att behandlas vid sjukdom. Detta görs av kostnadsskäl eftersom veterinärkostnaden i många fall blir högre än vad djurägaren är beredd att betala (Sköld Mariann muntligen, 2012).

I princip alla lamm som inte är avsedda för fortsatt avel går till slakt oavsett om rasen är avsedd för kött- eller ullproduktion. Vissa lamm, bland annat av pälsfårraser, har dock låg slaktvikt. Djuret kan utnyttjas i högre grad när både kött och skinn från sådana fårraser kan användas, men högre slaktvikt skulle kräva mer foder och innebära ett sämre skinn då slaktåldern blir högre. Eftersom skinn är huvudprodukten är detta ofta inte aktuellt. Getter slaktas, säljs och äts i liten omfattning i Sverige.

\section{Häst}

Endast en mindre andel av hästarna i Sverige går till slakt. De flesta avlivas för att sedan begravas, kremeras eller användas för energiproduktion. En del av de hästar som avlivas kan inte gå till slakt, då de tidigare har behandlats med läkemedel som inte får användas till livsmedelsproducerande djur. I en del andra fall vill ägaren inte att hästen ska gå till slakt av etiska eller känslomässiga skäl. Det finns dock potential att öka andelen hästar som går till slakt och därmed minska svinnet. Projektet Hästliv, som drivits av Hästnäringens nationella stiftelse och delfinansierats av Jordbruksverket, har analyserat detta ingående. 


\subsubsection{Mjölk och ägg}

\section{Ägg och Värphöns}

Värphöns kan slaktas och användas som mat, men de har relativt låg slaktvikt, och endast ett fåtal slakterier tar emot värphöns. Långa transporter kan innebära ett djurskyddsproblem. Alternativ till slakt för livsmedelsproduktion är slakt för foderproduktion, bland annat till minkfoder, och destruktion. Tuppkycklingar av värphönsras går i de flesta fall till destruktion redan som daggamla (Sköld Mariann muntligen, 2012).

Ägg destrueras p.g.a. skaldefekter eller sjukdomsutbrott. I Tabell 3 kan du se resultatet från ett examensarbete som har studerat anledningar till utsortering av ägg (Hollstedt, 2011).

\begin{tabular}{llr} 
Tabell 3: Svensk äggproduktion. Den genomsnittliga andelen svinn på grund av kvalitetsavvikelser \\
hos $\mathbf{4 5}$ äggproducenter med varierande produktionssystem (Hollstedt, 2011) \\
\hline Produkt & Typ av svinn & Andel svinn \\
\hline Ägg & Svinn i form av utsorterade ägg på grund av Knäckskador & $3 \%$ \\
Ägg & $\begin{array}{l}\text { Svinn i form av utsorterade ägg på grund av blod och kött- } \\
\text { fläckar, smuts }\end{array}$ & $0,05 \%$ \\
Ägg & $\begin{array}{l}\text { Svinn i form av utsorterade ägg på grund av att äggen av annan } \\
\text { anledning klassas som odugliga }\end{array}$ & $0,5 \%$
\end{tabular}

\section{Mjölk}

Komjölk kasseras för humankonsumtion framför allt p.g.a. att kon har behandlats med antibiotika. Mjölk kasseras också p.g.a. för höga celltal, ${ }^{1}$ bakterier eller sporer i mjölken. Råmjölk ska inte betecknas som ett svinn eftersom den behövs till kalven (Bergman, 2012). Mjölk är ett av fem fallstudieobjekt som beskrivs närmare i kapitel 4.

\subsubsection{Fisk och skaldjur}

Svinn inom yrkesfiske handlar framförallt om utkast av fisk på grund av kvoter, storleksgränser m.m. När det gäller vattenbruk däremot är svinnet kopplat till döda fiskar, rymningar, förstörelse och kassering från slakteri.

\section{Yrkesfiske}

En stor mängd ätbar fisk som tas upp på båtarna kastas tillbaka (Kelleher, 2005), se Tabell 4. Storleksgränser och uppfyllda fiskekvoter är orsaker till att fisk kastas tillbaka. Utkast är vanligast vid trålfiske och oftast överlever inte fiskarna denna behandling. I EU:s nya fiskerilagstiftning finns det ett

\footnotetext{
${ }^{1}$ Celltal används som ett begrepp inom mjölkproduktion och står för antal celler per milliliter mjölk. Dessa celler är i huvudsak olika vita blodkroppar vilka kan användas som en indikator för mjölkkons hälsotillstånd i juvret. Om mjölken har för högt celltal blir den klumpig.
} 
förslag till förbud mot utkast och att all fångst ska landas och räknas av kvoten för respektive fisk (Europa kommissionen, 13 juni 2012).

\begin{tabular}{llc} 
Tabell $\mathbf{4}$ Andel svinn vid yrkesfiske för olika typer av fiskemetoder & \\
\hline Produkt & Typ av svinn & Andel svinn \\
\hline Pelagisk fisk & Matsvinn i form av utkast från pelagisk trålning och not fiske & $2,3 \%$ \\
Bottenlevande fisk & Matsvinn i form av utkast från bottentrålning och långrev. & $9,5 \%$ \\
Annan fisk & $\begin{array}{l}\text { Matsvinn i form av utkast t från tonfiskfiske med not och } \\
\text { långrev, nätfiske, hand-lina och annan utrustning }\end{array}$ & $5,7 \%$ \\
Andra marina arter & $\begin{array}{l}\text { Matsvinn i form av utkast från övriga bland annat räktrål, } \\
\text { sediment muddring och spöfiske. }\end{array}$ & $22,2 \%$ \\
\hline
\end{tabular}

Värdena är de viktade medelvärden som anges i FAO:s studie för livsmedelsförluster och livsmedelssvinn (Gustavsson, Cederberg, Sonesson, \& Emanuelsson, 2013). De viktade medelvärdena är baserade på uppgifter från Kelleher (2005)

\section{Vattenbruk}

Svinn vid vattenbruk liknar det som uppstår vid köttproduktion. Framförallt handlar det om död fisk i kassarna men det kan också handla om att fåglar, sälar eller t.o.m. människor förstör systemen. Det händer också att fisk rymmer. Norska fiskeridirektorat för regelbunden statistik över död fisk, rymning och utkast från slakteri inom Norsk fiskodling. Det är ca 17 $\%$ svinn i primärproduktionen (Tekniskt Ukeblad, 2012). Ca 73 procent av svinnet i norsk fiskodling berodde 2011 på död i odlingen. Fyra procent berodde på utkast eller kassering från slakteri och mindre än en procent berodde på rymning. 22 procent av svinnet anges som "annat" och är inte specificerat (Fiskeridirektoratet, 2013).

Det går åt fler kilo fisk i fodret till odlad rovfisk (exempelvis lax) än vad man får ut i kilo producerad fisk (Olofsson \& Öhman, 2011). Eftersom fisken i fodret hade kunnat ätas direkt kan detta betraktas som ett svinn. Detsamma gäller även för vildfångad rovfisk. Foderkonverteringen har dock blivit bättre och man utvecklar nu fodermedel som t.ex. musslor.

\subsection{Växtodling och Trädgård}

Svinn i växtodling och trädgårdsodling beror framförallt på förluster vid skörd, kvalitetsförändringar vid lagring och sortering på grund av utseende eller andra defekter. En annan orsak till svinn är viktminskning vid lång lagringstid.

En del rotfrukter och potatis lämnas i fält avsiktligt. Det kan bero på att de har fel storlek, är skadade eller insektsangripna. Lagringskador hänger ofta ihop med mekaniska skador i fält. Om grödorna lagras en längre period blir problemet med mekaniska skador större. Lagringssjukdomar orsakar också svinn (Holstmark Katarina muntligen, 2012)

En annan orsak till utsortering kan vara att konsumenterna väljer bort fula produkter. Kravet på kosmetiskt sett bra produkter kan i praktiken 
vara starkare än de formella regler som finns i EU:s eller FN:s handelsnormer och odlare kan rensa bort produkter redan på sorteringsbandet för att undvika klagomål och returer. Den allmänna handelsnormen gäller för i stort sett alla frukter och grönsaker. Den säger i stort sett bara att produkterna ska vara av sund, god och marknadsmässig kvalitet. För tio produkter gäller specifika handelsnormer med detaljerade krav om hur produkterna ska se ut och märkas. Även för andra produkter gäller sådana detaljerade krav om produkten ska märkas som exempelvis Klass I, eftersom den allmänna handelsnormen då ersätts med FN:s produktspecifika normer (Johansson Katarina muntligen, 2012).

Potatis omfattas inte av någon kvalitetsnorm inom EU. Ändå har handeln i stort sett samma krav på utseende och storlek. Detta talar för att det inte nödvändigtvis är normerna i sig som är drivande utan även handelns och konsumenternas krav.

Lågt marknadsvärde eller att det saknas avsättning för produkterna kan vara en orsak till att man låter bli att skörda. Två exempel på produkter där det förekommer är isbergsallat och bärodling (Winter Christina muntligen, 2012).

\subsubsection{Spannmål}

Förluster vid spannmålsodling på grund av tröskspill ligger på runt 3 \%. De totala produktionsförlusterna kan dock vara betydligt större till följd av bl.a. ogräskonkurrens, växtskadegörare m.m. Tabell 5 visar exempel på uppmätta förluster vid odling av spannmål framförallt vid svenska förhållanden.

Tabell 5: Kvantifierat produktionsförluster i spannmålsodling enligt litteraturuppgifter

\begin{tabular}{|c|c|c|c|}
\hline Produkt & Typ av svinn & Andel svinn & Förklaring och källa \\
\hline Vete & $\begin{array}{l}\text { Produktionsförlust i form } \\
\text { av tröskspill }\end{array}$ & $\begin{array}{l}\text { Höstvete: } 2,9 \% \\
\text { Vårvete: } 3,1 \%\end{array}$ & $\begin{array}{l}\text { Svensk odling. Bärgningssiffror vad blir } \\
\text { kvar i fält vid skörd på grund av spill } \\
\text { vid tröskning. Siffrorna är standardtal } \\
\text { framtagna vid fältförsök från } 1993 \\
\text { (SCB, 1993). }\end{array}$ \\
\hline Råg & $\begin{array}{l}\text { Produktionsförlust i form } \\
\text { av tröskspill }\end{array}$ & $3,3 \%$ & Se ovan \\
\hline $\begin{array}{l}\text { Havre, } \\
\text { blandsäd, } \\
\text { rågvete }\end{array}$ & $\begin{array}{l}\text { Produktionsförlust i form } \\
\text { av tröskspill }\end{array}$ & $\begin{array}{l}\text { Södra Sverige: 3,7 \% } \\
\text { Norra Sverige 4,2 \% }\end{array}$ & Se ovan \\
\hline Korn & $\begin{array}{l}\text { Produktionsförlust i form } \\
\text { av tröskspill }\end{array}$ & $\begin{array}{l}\text { Södra Sverige: } 3,7 \% \\
\text { Norra Sverige 5,9 \% }\end{array}$ & Se ovan \\
\hline Korn & $\begin{array}{l}\text { Produktionsförlust i form } \\
\text { av ospecificerad skörde- } \\
\text { förlust }\end{array}$ & $0,07-2,8 \%$ & $\begin{array}{l}\text { Kanadensisk odling, som har studerat } \\
\text { skördeförluster. Det framgår inte om } \\
\text { endast tröskspill är med eller om } \\
\text { exempelvis bärgning m.m. är inräknat. } \\
\text { Siffran för svinn är under optimala } \\
\text { förhållanden, det anges att under } \\
\text { sämre förhållanden kan så mycket } \\
\text { som upp till } 6 \text { \% av kornen gå till spillo } \\
\text { (Smil, 2004). }\end{array}$ \\
\hline
\end{tabular}




\subsubsection{Oljeväxter}

För oljeväxter är förlusterna vid skörd mellan 2-5 \% enligt den litteratur som funnits tillgänglig, seTabell 6. I litteraturen finns inte specificerat vad skördeförlusterna beror på.

Tabell 6: Uppgifter om svinnet för odling av oljeväxter från litteratur.

\begin{tabular}{|c|c|c|c|}
\hline Produkt & Typ av svinn & Andel svinn & Förklaring och källa \\
\hline $\begin{array}{l}\text { Raps, rybs och } \\
\text { andra oljefröslag }\end{array}$ & $\begin{array}{l}\text { Produktionsförlust i } \\
\text { form av ospecificerad } \\
\text { skördeförlust }\end{array}$ & $3 \%$ & $\begin{array}{l}\text { Uppgift från svenska producentorganisation- } \\
\text { erna som används för att beräkna produkt- } \\
\text { ionsförlusterna i rapporteringen till EAA. } \\
\text { Uppgiften kommer från metodbeskrivningen } \\
\text { för ekonomisk kalkyl för jordbrukssektorn. } \\
\text { (Jordbruksverket, 2006). }\end{array}$ \\
\hline Oljefrö & $\begin{array}{l}\text { Produktionsförlust i } \\
\text { form av ospecificerad } \\
\text { skördeförlust }\end{array}$ & $2-5 \%$ & $\begin{array}{l}\text { Skördeförlust vid odling av oljefrö i Storbri- } \\
\text { tannien, vid optimala förhållanden anges } 2-5 \\
\% \text {, men det har observerats så höga förluster } \\
\text { som } 20-25 \% \text { (Hobson \& Bruce, 2002). }\end{array}$ \\
\hline
\end{tabular}

\subsubsection{Potatis och grönsaker}

Det finns flertalet studier på olika grönsaker som har tittat på säljbar andel av den totala skörden. Enligt tillgänglig litteratur ger dill, vitkål, lök och tomat upphov till relativt stor svinnandel på mellan $10-30 \%$ av den totala produktionsvolymen. Beroende på vad potatisen ska användas till varierar det uppkomna svinnet. Det största svinnet uppstår för matpotatis på grund av stortering efter skörd. Morot, lök och potatis är fallstudieobjekt, se kapitel 4 . Tabell 7 visar uppgifter på svinn vid produktion av potatis och grönsaker.

Tabell 7: Svinn för potatis och grönsaker i procent av total skörd, Sverige.

\begin{tabular}{|c|c|c|c|}
\hline Produkt & Typ av svinn & Andel svinn & Förklaring och källa \\
\hline Potatis, mat & $\begin{array}{l}\text { Svinn i form av sortering efter } \\
\text { skörd }\end{array}$ & $9,5 \%$ & $\begin{array}{l}\text { Svensk odling, baserat på uppgifter } \\
\text { från 1987-1998 års objektiva skörde- } \\
\text { uppskattningar på produktionsområ- } \\
\text { desnivå och för riket. Bortsortering av } \\
\text { småfallande och t.ex. rötskadade } \\
\text { knölar (Ländell \& Wahlstedt, 2012) }\end{array}$ \\
\hline Potatis, stärkelse & $\begin{array}{l}\text { Svinn i form av sortering efter } \\
\text { skörd }\end{array}$ & $0,4 \%$ & Se ovan \\
\hline Potatis, färsk & $\begin{array}{l}\text { Svinn i form av sortering efter } \\
\text { skörd }\end{array}$ & inget svinn & Se ovan \\
\hline Morot & $\begin{array}{l}\text { Svinn i form av säljbar andel } \\
\text { efter lagring och sortering }\end{array}$ & $\begin{array}{l}\text { 25-30 \% (både } \\
\text { ekologisk och } \\
\text { konventionell) }\end{array}$ & $\begin{array}{l}\text { Svensk produktion. Den säljbara } \\
\text { andelen motsvarar ett årsmedeltal för } \\
\text { lagrade produkter, och säljbar andel } \\
\text { är således högre vid försäljning efter } \\
\text { korttidslagring(Jordbruksverket, } \\
\text { 2009). För morötter som inte lagrats } \\
\text { har svinnet beräknats till } 25 \% \\
\text { (Gustavsson, Cederberg, Sonesson, \& } \\
\text { Emanuelsson, 2013) baserat på } \\
\text { uppgifter i (Davis, M, V, A, Cederberg, } \\
\text { \& Sonesson, 2011) }\end{array}$ \\
\hline
\end{tabular}




\begin{tabular}{|c|c|c|c|}
\hline Produkt & Typ av svinn & Andel svinn & Förklaring och källa \\
\hline Rödbeta & $\begin{array}{l}\text { Svinn i form av säljbar andel } \\
\text { efter lagring och sortering }\end{array}$ & $\begin{array}{l}\text { Ekologisk: } 25 \% \\
\text { Konventionell: } 20 \%\end{array}$ & Se ovan \\
\hline Vitkål & $\begin{array}{l}\text { Svinn i form av säljbar andel } \\
\text { efter lagring och sortering }\end{array}$ & $\begin{array}{l}\text { Ekologisk: } 30 \% \\
\text { Konventionell: } 15 \%\end{array}$ & $\begin{array}{l}\text { Svensk produktion. Den säljbara } \\
\text { andelen motsvarar ett årsmedeltal för } \\
\text { lagrade produkter, och säljbar andel } \\
\text { är således högre vid försäljning efter } \\
\text { korttidslagring.(Jordbruksverket, } \\
\text { 2009) }\end{array}$ \\
\hline Lök & $\begin{array}{l}\text { Svinn i form av säljbar andel } \\
\text { efter lagring och sortering }\end{array}$ & $\begin{array}{l}16-20 \% \text { (både } \\
\text { ekologisk och } \\
\text { konventionell) }\end{array}$ & $\begin{array}{l}\text { Svensk produktion. Den säljbara } \\
\text { andelen motsvarar ett årsmedeltal för } \\
\text { lagrade produkter, och säljbar andel } \\
\text { är således högre vid försäljning efter } \\
\text { korttidslagring (Jordbruksverket, } \\
\text { 2009). Sortering efter skörd beräknas } \\
\text { ge upphov till svinn på } 16 \% \text {, beräknat } \\
\text { av (Gustavsson, Cederberg, Sonesson, } \\
\text { \& Emanuelsson, 2013) baserat på } \\
\text { uppgifter i (Davis, M, V, A, Cederberg, } \\
\text { \& Sonesson, 2011) }\end{array}$ \\
\hline Tomat & Svinn vid sortering efter skörd & $10-15 \%$ & $\begin{array}{l}\text { Svensk tomatodling, beräknat av } \\
\text { (Gustavsson, Cederberg, Sonesson, \& } \\
\text { Emanuelsson, 2013) baserat på } \\
\text { uppgifter i (Davis, M, V, A, Cederberg, } \\
\text { \& Sonesson, 2011) }\end{array}$ \\
\hline $\begin{array}{l}\text { Köksväxter på } \\
\text { friland }\end{array}$ & $\begin{array}{l}\text { Produktionsförluster på } \\
\text { grund av oskördad areal }\end{array}$ & $1-5 \%$ & $\begin{array}{l}\text { Svensk odling, Areal som inte skördas } \\
\text { är mellan 1-5 \% (Jordbruksverket, } \\
\text { 2012). }\end{array}$ \\
\hline Dill och Vitkål & $\begin{array}{l}\text { Produktionsförluster på } \\
\text { grund av oskördad areal }\end{array}$ & $15 \%$ & $\begin{array}{l}\text { Svensk odling. Areal som inte skördas } \\
\text { är runt } 15 \% \text { (Jordbruksverket, 2012) }\end{array}$ \\
\hline
\end{tabular}

\subsubsection{Frukt och bär}

Äpple uppges ha ett svinn på mellan 2-5 procent enligt litteraturen. Det finns lite tillgänglig data om jordgubbar, men muntliga uppgifter tyder på att svinnet kan vara stort under varma somrar. Tabell 8 visar uppgifter på svinn vid produktion av frukt och bär.

Tabell 8: Uppgifter på svinn för frukt och bär

\begin{tabular}{llll}
\hline Produkt & Typ av svinn & Andel svinn & Förklaring och källa \\
\hline Äppelodling & Svinn vid skörd & $1,8 \%$ & $\begin{array}{l}\text { Svensk kommersiell produktion. (Börjesson, } \\
\text { 2012) }\end{array}$ \\
& Svinn vid sortering & Konventionell: $2 \%$ & $\begin{array}{l}\text { Svensk äppelodling. Svinn efter skörd innan } \\
\text { odlarens försäljning (Jordbruksverket, 2010) }\end{array}$ \\
Jordgubbar & Svologisk: $5 \%$ & $\begin{array}{l}\text { Andelen svinn är beroende av vädret. Om det är } \\
\text { kallt är det knappt något svinn alls, medan } \\
\text { svinnet ökar vid högre temperaturer } \\
\text { (Hogstadius Calle muntligen, 2012) Det kan även } \\
\text { bli svinn i partihandeln (Engstedt Magnus } \\
\text { muntligen, 2012) }\end{array}$ \\
\hline
\end{tabular}




\section{Fem fallstudier}

Vi har gjort en grundligare datainsamling av svinn inom fem vanliga produktgrupper: potatis, pök, morot, mjölk och griskött. Av tidsskäl har vi tagit fram nyckeltal på andel av svinn för en produkt i ett land och sedan applicerat detta på den totala produktionen i hela Norden. Vi har studerat finsk potatisodling, norsk odling av morötter och lök, svensk mjölkproduktion och dansk uppfödning av griskött. De fyra studierna finns som bilagor till rapporten.

\subsection{Metod}

En viktig del av metoden var att definiera vad som ska räknas som svinn inom primärproduktionen. Detta beskrivs i kapitel 2.

Tillvägagångsättet för kartläggningen har sedan varit:

1. Ta fram nyckeltal för produkterna genom fallstudier .

2. Ta fram data på total produktion för alla fyra länder.

3. Beräkna jämförelsetal för produkterna.

4. Jämföra.

För de olika produktgrupperna har vi haft olika möjlighet att få tillgång till uppgifter på ett smidigt sätt. Därför skiljer sig avgränsningarna och detaljupplösningen mellan grupperna. I vår studie rör vi oss inom de tre första boxarna av livsmedelskedjan enligt Figur 2. Vår studie innefattar alltså både oavsiktliga förluster i början av livsmedelskedjan, såsom sjukdomar hos djur eller förluster vid lagring, och avsiktligt svinn i början av livsmedelskedjan, t.ex. bortgallring av produkter med fel form, men som fortfarande är fullt ätbara. Vi väljer här att använda begreppet svinn både för förluster och för matsvinn i produktionsledet. 
Figur 2: Beskrivning av hur de fem kartläggningsstudierna förhåller sig till FAOs indelning av livsmedelskedjan

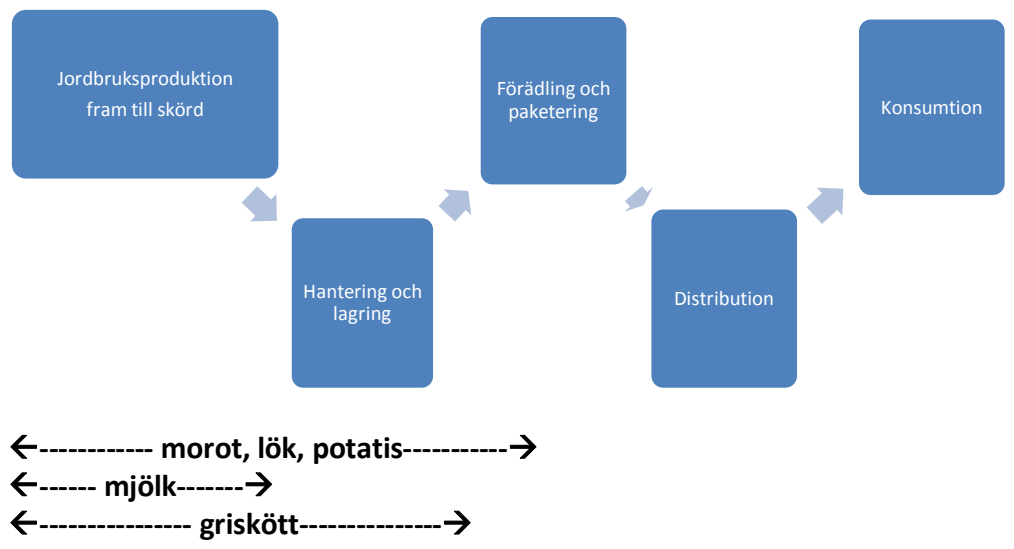

För morot och lök upptäcks svinn i odlingen oftast inte förrän de ska paketeras. Alltså innefattar vår studie förluster och svinn ända från sjukdomar som uppstår i fält, förluster vid skördetillfället och lagringsförlusterna i en och samma svinnsiffra. För att göra en finare uppdelning än så krävs en mer djupgående studie. Det finns siffror presenterade på hur många procent som blir kvar i fält och hur stort svinnet är efter lagring, men alla skador som uppstår i fält upptäcks inte förrän efter lagring. Potatis har samma systemgräns som morötter och lök. Alla tre produktgrupperna innefattar alltså den första, andra och delar av tredje boxen. Det som i studien inte ingår av tredje boxen är svinn som uppstår då de skalas eller skivas.

För mjölk har studien gjorts på gården och vi håller oss helt och hållet inom den första boxen. För griskött har vi haft tillgång till statistik från uppfödning till slakt och statistiken är uppdelad på förluster på gårdsnivå, transport till slakteri och kassering vid slakt, alltså de två första boxarna.

\subsection{Datainsamling}

Datainsamlingen skiljer sig mellan produktgrupperna. När det gäller grisproduktionen i Danmark baseras dessa data på nationell statistik som har samlats in från grisgårdar i hela landet. När det gäller de övriga produktgrupperna fann ingen sådan statistik, så data samlades in direkt från aktörerna; bönder, experter och packerier. Det finns många grönsaks-, potatisoch mjölkproducenter i Norge, Finland och Sverige. Därför gjordes ett urval av producenter för undersökningen. Metoden för att fă ett så representativt urval som möjligt beskrivs i bilagorna för varje produktgrupp.

Det hade varit idealt om undersökningarna hade genomförts genom faktiska mätningar i fält, eller genom studier av data från sådana mätningar. I Norge, Sverige och Finland fanns inga register från sådana mätningar och i projektet fanns inte resurser till att göra några fältundersökningar. Det innebar att vi tvingades göra antaganden kring de data 
som samlades in från de involverade aktörerna och det finns därför en viss osäkerhet kring dessa data.

De uppgifter som använts till att beräkna den totala produktionen och priser baseras till stor del på nationell jordbruksstatistik i de fyra länderna. Priserna som har använts i beräkningarna av ekonomisk förlust är de priser som lantbrukarna skulle ha fătt för sin produkt, om den kunnat säljas. I resultaten redovisas alltså lantbrukarnas ekonomiska förlust på grund av svinn.

Den "förlorade arealen" är den markareal som krävs för att producera den mängd mat som går förlorad i primärproduktionen. För mjölk och griskött är även arealer för foderproduktion inräknade. "Förlorad areal" innebär givetvis inte att arealen gått förlorad, utan snarare att jorden under ett år tagits i anspråk med syfte att producera mat, men där produktionen inte går till humankonsumtion. Detta är en viktig aspekt för alla länder, men framför allt för länder som är beroende av importerad mat, som till exempel Norge. Norge har dessutom som mål att öka den inhemska matproduktionen.

Klimatpåverkan relaterat till mängden svinn har beräknats från produktionen på gården och följer samma avgränsning som respektive kartläggning. Klimatpåverkan som följer av slutlig hantering eller transporter av produkterna är inte medräknade i undersökningen. Inte heller den påverkan som har undvikts är medräknad. En sådan kan till exempel vara att djuren har utfodrats med morötter som inte gått att sälja. Klimateffekterna av att ta tillvara svinn är mycket små jämfört med klimateffekterna av att svinnet aldrig hade uppstått (Röös, Sundberg, \& Hansson, 2010); (Cederberg, Sonesson, Henriksson, Davis, \& V, 2009); (Davis, M, V, A, Cederberg, \& Sonesson, 2011); (Gustavsson J. , 2010); (Maten och miljön - Livscykelanalys av sju livsmedel, 2011).

De uppgifter som använts i beräknandet av förlorad areal och klimatpåverkan baseras på ett begränsat antal studier. Syftet med dessa beräkningar är endast att peka på problemets storlek.

I alla fallstudierna har vi försökt göra så goda uppskattningar som möjligt. Till exempel har data som reflekterar långsiktiga medelvärden efterfrågats. I vissa fall har man tagit hänsyn till att information har samlats in från de stora produktionsområdena i länderna. Ekologisk produktion har inte undersökts förutom för mjölken där både ekologiska och konventionella gårdar finns med i undersökningen. 


\subsection{Resultat}

\section{Andel svinn}

Svinn i morots-, lök- och potatisodling kan klassas antingen som svinn på åkern eller lagringssvinn. En del morötter och lök blir kvar på åkern vid skörd och en del plockas bort efter lagring. För norsk odling av morot var svinnet på åker 1,6 procent av skörden och lagringssvinnet 25 procent av det som lagrats. För lök var motsvarande siffror 1 procent och 13 procent. För finsk potatis blir ca 5 procent kvar i jorden vid skörd och upp till 15 procent av potatisen som skördas går inte till humankonsumtion. Trots att det kan vara svårt att minska svinnet på åkern finns det möjliga åtgärder för en minskning. För lagringssvinnet finns en potential att minska detta genom att hitta marknader för produkter med fel form och storlek, minska angrepp av sjukdomar och förbättra lagringsmiljön och rotation i lagret. Ett visst svinn är dock alltid oundvikligt.

\subsubsection{Morot}

\section{Orsaker}

Den främsta anledningen till svinn för morötter är fel storlek och form, fläckar och färgavvikelse. Storleksmässigt kan produkterna både vara för stora och för små, men stora morötter går ofta att sälja till storkök. En vanlig formavvikelse är dubbla rötter. En av fyra ledande livsmedelskedjor i Norge accepterar morötter med avvikelse i storlek eller form i sina egna lågprismärken. Fläckar eller färgavvikelse kan bero på allt från små fläckar som inte påverkar smaken till stora ruttna områden. Den huvudsakliga orsaken är sjukdomar.

Andra skäl till svinn är mekaniska skador eller sprickor i morötterna. Mekaniska skador uppstår vid skörd och hantering av morötterna efter skörd. Sprickor uppkommer oftast när morötterna växer och beror på väderförhållanden. Det har inte varit möjligt att få storleken på svinnet uppdelat på vardera av skälen som anges ovan.

\section{Möjliga åtgärder för minskat svinn}

Alla producenter använder sig av växtföljd i odlingen. En producent nämnde att odlarens skicklighet är en viktig faktor för att hålla nere svinnet. En annan nämnde att dränering och ökad acceptans för olika storlek och form är de viktigaste åtgärdena för att få ner svinnet. 


\subsubsection{Lök}

Orsaker

De främsta orsakerna till svinn är lökar som har ruttnat, mekaniska skador, för små lökar och små skönhetsfläckar, såsom färgavvikelse. Den främsta av dessa orsaker är lökar som har ruttnat. En producent sa att lökflugan var en bidragande orsak till detta. Eftersom lök inte kan användas till foder komposteras den lök som sorteras bort i de flesta fall. Om löken inte kan komposteras på den plats den produceras måste den gå till deponi, vilket är en stor kostnad för producenterna.

\section{Möjliga åtgärder för minskat svinn}

Liksom för morötter är den främsta förbättringsmöjligheten att kunna sälja lök som går att äta, men som av olika anledningar ratas av grossister och butiker. Kvaliten på lök kan också bli bättre med förbättrad torkningsteknik och bättre reglering av temperatur vid lagring. Lök ska torkas vid så låg temperatur som möjligt och hållas kyld åtminstone från mars-april och framåt. De tillfrågade odlarna trodde inte att förändrad växtföljd eller odlingsmetoder påverkar mängden svinn nämnvärt.

\subsubsection{Potatis}

Orsaker

Två av de främsta anledningarna till svinn är väderförhållanden och att små potatisar lämnas på åkern. De små potatisarna smakar inte annorlunda, men klassas ändå som klass II-produkter. Det är därför inte lönsamt att plocka upp små potatisar, trots att det skulle kunna vara tekniskt möjligt att plocka upp dem maskinellt.

En annan viktig orsak till svinn är undermåliga lagringsförhållanden, såsom fel temperatur, syretillgång och luftfuktighet. Även vid optimala lagringsförhållanden tappar potatis 6-7 procent av sin vikt när den lagras över vintern. Vid sämre lagringsvillkor kan den tappa upp emot 20 procent av vikten.

Uppköparnas kvalitetskrav påverkar också mängden svinn. Det finns t.ex. krav på att potatis ska hålla sig inom storleksspannet 30-60 mm och att alla potatisar i samma parti ska vara lika stora. Dessutom får de inte ha några fläckar eller märken.

\section{Möjliga åtgärder för minskat svinn}

Det finns många sätt att minska på svinnet i potatisodlingen. Några exempel kan vara växtföljd och bättre struktur på jorden. Olika potatissorter har också olika egenskaper som kan vara viktigt att ta hänsyn till vid odling. Större försiktighet vid skörd och vid hantering efter skörd är också något som lyfts fram som viktiga faktorer för att minska svinnet. Bättre teknisk utrustning kan minska denna typ av skador. 
Genom att installera utrustning som ger en bättre lagringsmiljö går det att minska svinnet vid lagringen av potatis. Att lagra den potatis som är av bäst kvalité och hitta bättre användningsområden för den med sämre kvalité kan också vara ett sätt att minska lagringssvinnet.

\subsubsection{Mjölk}

Den främsta orsaken till svinn inom mjölkproduktionen är att korna har behandlats med antibiotika. Mjölken får då inte skickas till mejeriet, utan denna hamnar i gödselbrunnen eller ges till kalvarna. Andra orsaker till svinn kan vara sjukdomar som ger mjölk av dålig kvalitet eller mjölk som förstörs i mjölktanken olika anledningar. De senare problemen är dock väldigt små i jämförelse.

\section{Möjliga åtgärder för minskat svinn}

Det finns olika uppfattning om huruvida mjölk från antibiotikabehandlade kor kan ges till kalvar eller inte i Sverige, där ungefär hälften av mjölkbönderna inte ger sådan mjölk till kalvar över huvud taget. Vissa mjölkbönder ger den enbart till tjurkalvarna medan några ger den till alla kalvarna. Några ger kalvarna endast den mjölken som mjölkas under karenstiden och inte under själva behandlingstiden.

Bästa sättet att minska mjölksvinnet är att ha god djurhälsa för att hålla nere behandlingen med antibiotika i besättningen. Det är problematiskt att ge antibiotikakontaminerad mjölk till kalvar med tanke på att det kan ge upphov till antibiotikaresistans hos djuren. Det pågår en studie vid Sveriges Lantbruksuniversitet (SLU), där man studerar effekterna och konsekvenserna av att ge mjölk från antibiotikabehandlade kor till kalvar. Att ge mjölk som produceras under karenstiden till kalvarna är mindre kontroversiellt och skulle kunna vara ett sätt att minska svinnet, men även under karenstiden kan det finnas antibiotikarester i mjölken.

\subsubsection{Griskött}

Ungefär 5 procent av grisarna (levandevikt) som produceras i Danmark går inte till slakt. Räknat i antal djur kommer de högsta siffrorna från kultingarna, men de utgör inte så stor andel av levandevikten, endast 13 procent. Störst andel av levandevikten som inte går till slakt utgör slaktfärdiga grisar (49 procent). Det är angeläget att få ner andelen döda djur både ur djurvälfärdsperspektiv och ur ett ekonomiskt perspektiv. Andelen slaktsvin och suggor som dör vid transport till slakteriet är väldigt låg i procent, 0,01 respektive 0,07 procent. Andelen som ratas vid slakteriet är också låg, 0,18 respektive1,21 procent. Inte desto mindre är det angeläget att jobba för att minska dödligheten även i dessa led i kedjan. 


\section{Möjliga åtgärder för att minska svinnet}

Minskat svinn jämställs här med minskad dödlighet på gården. I den danska grissektorn finns ett mål att minska dödligheten med 20 procent till 2020. Målet ska uppnås genom följande initiativ:

- Avla på högre överlevnad hos kultingar.

- Förbättra modersegenskaper för att kunna föda upp 14 slaktfärdiga kultingar per kull.

- Skapa bättre strategier för att kunna hantera stora kullar.

- Förbättra miljön i grisstallarna.

- Använda barriärer för att förhindra spridning av sjukdomar mellan grupper av grisar.

- Använda handböcker för att förbättra arbetsrutinerna i grisstallarna.

- Avla på förbättrad livslängd och benstyrka hos suggorna.

\section{Jämförelse av griskött i de nordiska länderna}

Resultaten för griskött baseras på data från Danmark. Baserat på statistik över döda djur och produktivitet för Sverige och Norge, kan en jämförelse av svinnet göras mellan dessa två länder och Danmark.

\begin{tabular}{lrrr} 
Tabell 9: Andel svinn för griskött i Danmark, Sverige och Norge & & \\
\hline Land & Danmark & Sverige & Norge \\
\hline Andel svinn (procent av produktionen i kilo) & 3,1 & 1,8 & 2,0 \\
Andel svinn (procent av det ekonomiska värdet av produktionen) & 10,9 & 7,9 & 7,4
\end{tabular}

Döda suggor och export av levande djur ingår inte i siffrorna i tabellen. I beräkningarna antas andelen döda suggor och mängden exporterade levande djur vara samma per kull för de olika länderna. Om vi i stället antar att ingen export görs från Sverige och Norge blir andelen svinn baserat på vikt runt 1,9 \% för båda dessa länder. Andelen svinn skiljer sig mellan länderna, både om med avseende på vikt och på värdet i pengar. Danmark har signifikant högre andel svinn än Norge och Sverige. Värdena för Finland kunde inte beräknas på grund av otillräckliga data.

En jämförelse av antalet kultingar födda per kull gjordes också mellan de tre länderna. År 2011 hade Danmark 13,6 procent fler kultingar per kull än Sverige och 11,4 procent fler än Norge. Detta är intressant med tanke på att Danmark har det största svinnet och att svinnet är särskilt stort hos kultingarna

\subsubsection{Jämförelse mellan produktgrupperna}

Det är vanskligt att jämföra de olika produktgrupperna i samma tabell, eftersom olika definition och metod har använts för att få fram siffrorna. Andelen svinn är mycket högre för morot, lök och potatis än för griskött och mjölk, vilket delvis beror på att lagringssvinnet är med i beräkningarna. Mängden mjölk som har avvisats på mejeriet inkluderades inte och 
inte heller mjölksvinn som kan ha uppstått under senare delen av värdekedjan. Mängden grisar som avvisades på slakteriet noterades, men inte det svinn som uppstod efter det att kultingarna hade slaktats.

Figur 3 visar att andelen svinn är relativt hög för grönsaker och potatis. Den högsta andelen noteras för morötter. För mjölk är den liten, vilket till viss del beror på gränsdragningen, men det är inte den enda orsaken. Svinnet av mjölk är väldigt litet jämfört med griskött även då de har samma avgränsning.

Figur 3. Procentuell andel svinn för respektive produkt, morot, lök, potatis, mjölk och griskött

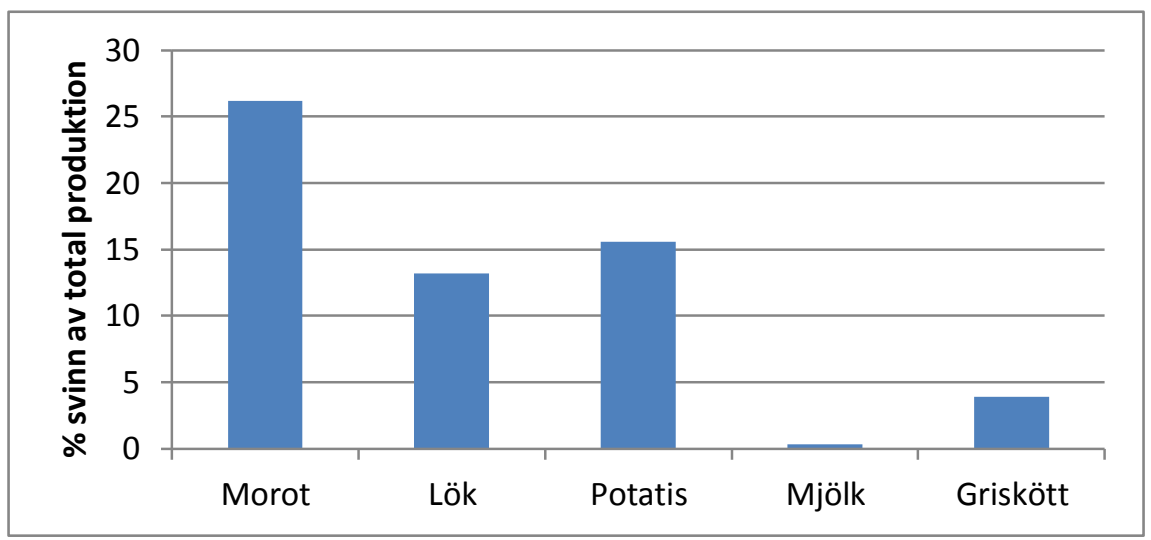

Figur 4 visar siffrorna för den totala mängden svinn (i ton) i de fyra nordiska länderna, baserat på nationella data för produktion. Produktionsvolymerna är betydelsefulla för hur stor den totala mängden svinn blir. Potatis har mycket högre totalt svinn än morötter, även om morötter har högre andel svinn. Detta beror på att produktionen av potatis är mycket högre än produktionen av morötter. Likaså är produktionsvolymen av fläsk och mjölk mycket hög, medan produktionsvolymen av lök är väldigt låg.

Figur 4. Mängden svinn i ton per år för de fem produktgrupperna

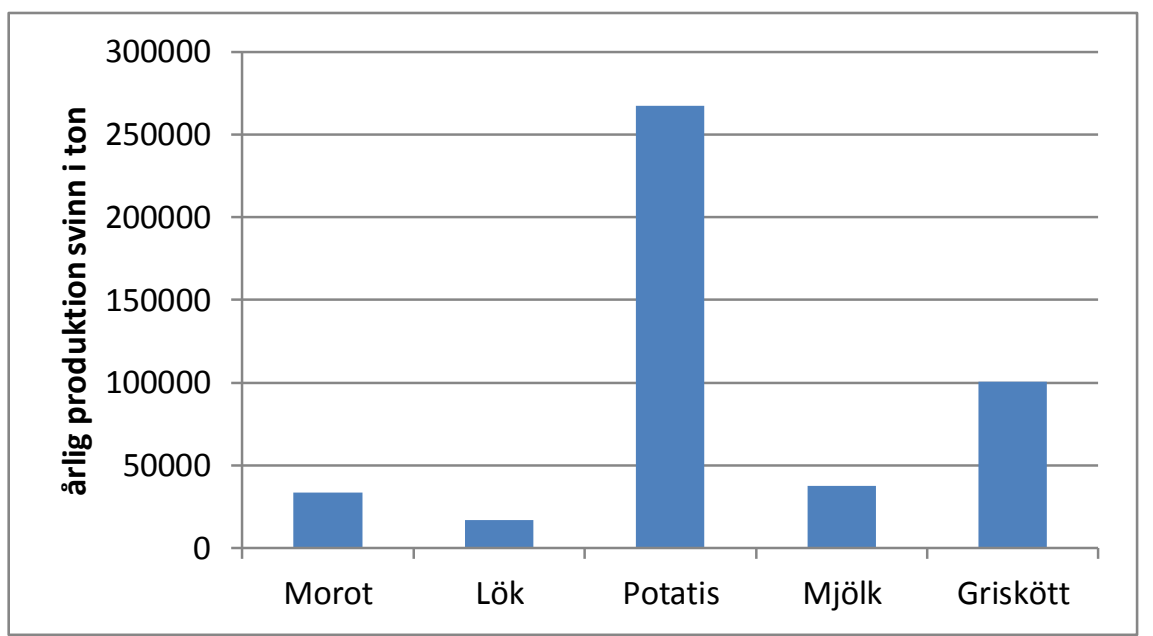


Figur 5 visar det ekonomiska värdet av svinnet. När det gäller ekonomiskt bortfall är stapeln för griskött väldigt hög på grund av att det ekonomiska värdet på griskött är högt.

Figur 5. Ekonomiskt värde av svinnet för de fem produktgrupperna

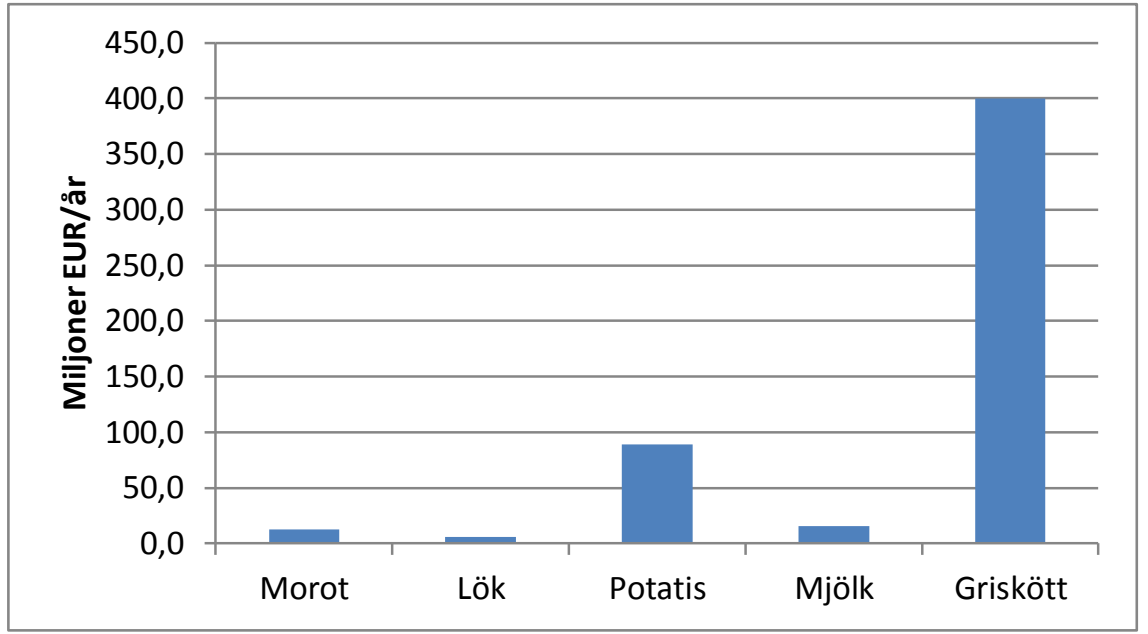

Resultaten för den "förlorade arealen" visas i Figur 6. För att producera griskött krävs stora arealer. Arealerna för att producera morötter och lök är väldigt små.

Figur 6. Den areal som krävs för att producera morot, lök, potatis, mjölk och griskött

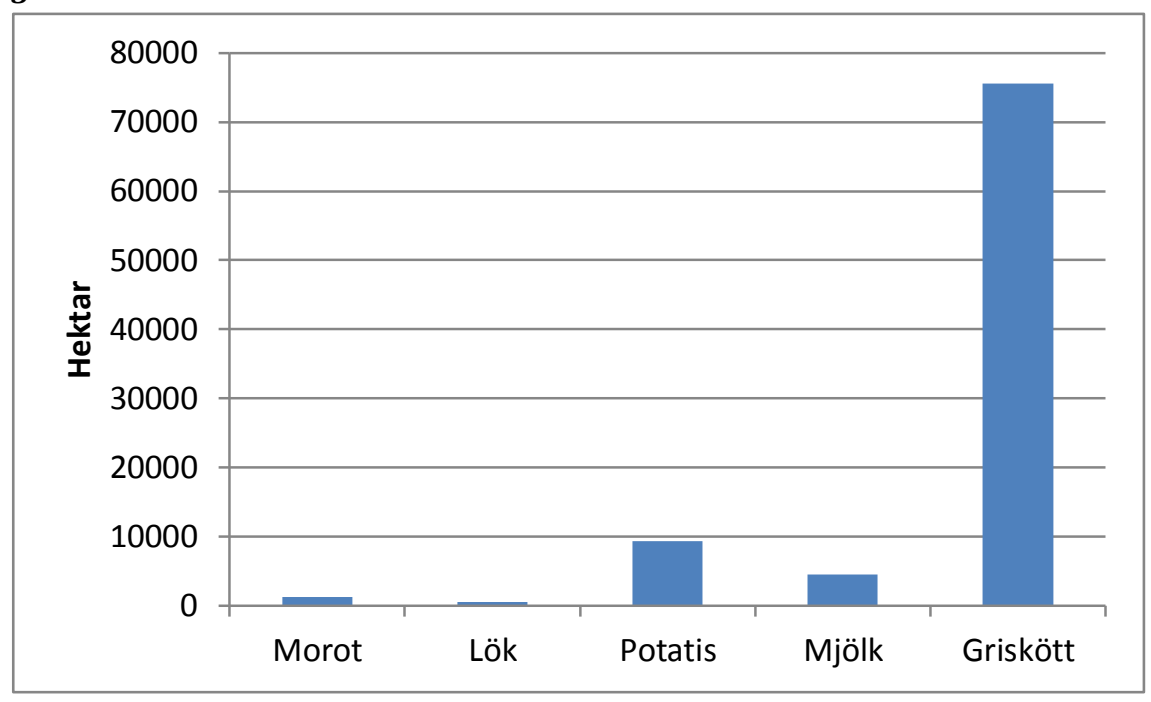


Figur 7 visar den klimatpåverkan svinnet har. Inverkan från vegetabilier är obetydliga i jämförelse med animaliska produkter. Vår studie visar att klimatpåverkan från lök, morot och potatis nästan är helt obetydlig jämfört med framför allt griskött.

Figur 7. Klimatpåverkan av svinnet från de fem produktgrupperna

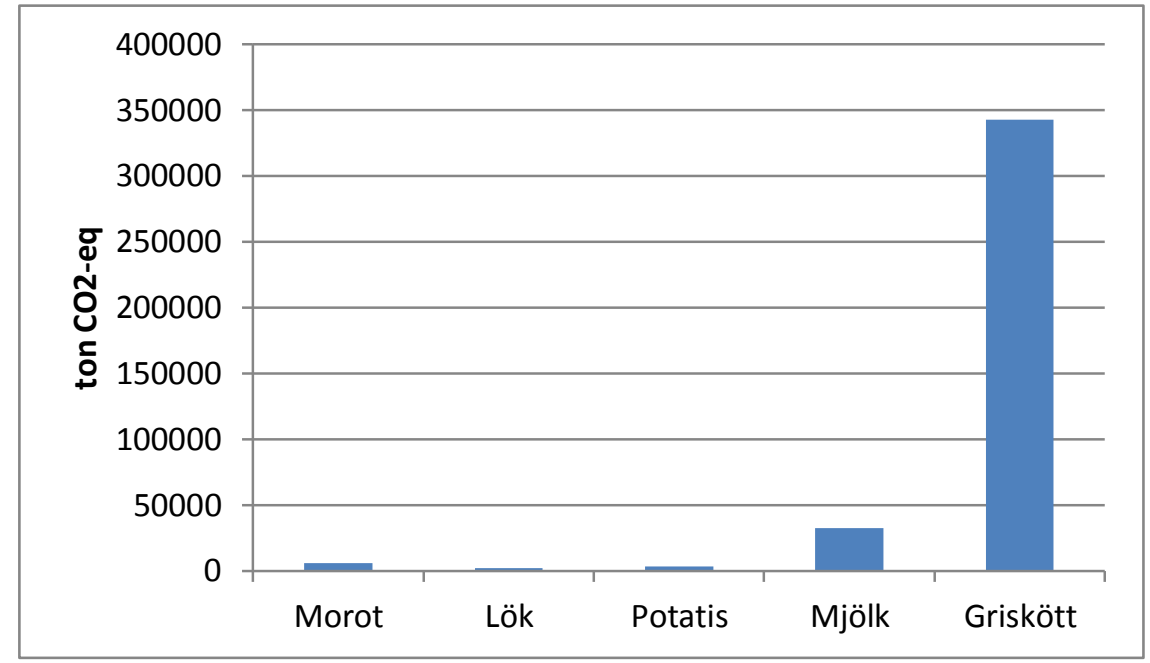

\subsection{Diskussion av fallstudierna}

Med tanke på skillnaden i systemgräns för de olika produktgrupperna är det svårt att jämföra dem sinsemellan. Det är ändå tydligt att det är mer svinn hos morot, lök och potatis än hos griskött och mjölk. En betydande faktor är troligen det faktum att potatis, morötter och lök lagras under långa perioder innan de hanteras, medan mjölk och kött oftast behandlas relativt snart efter att de producerats (mjölkats eller slaktats). Detta intygas av packerierna, som rapporterar stora skillnader i svinn mellan produkter som förvaras under korta respektive långa perioder. (Bengtsson, Sørensen, Martinsen, \& Tandberg, 1996)

En annan orsak kan vara att skillnaden i kvalitet mellan t.ex. kött från olika djur är mindre än skillnaden i kvalitet mellan t.ex. olika morötter. En morot med fel storlek kan också avvisas och bli till svinn, medan griskött av olika storlek accepteras i högre utsträckning. Prisskillnader kan också tänkas påverka hur stort svinnet blir. Det är mer kostsamt att låta dyra produkter gå till spillo än billiga.

Exemplet med griskött visar att antagandet om att andelen produktionsförluster är lika i de nordiska länderna är felaktigt. Förlusterna var högre i Danmark än i Norge och i Sverige. Effekten var mycket större för vikt än ekonomiskt värde. En orsak kan vara att dödstalet för kultingar skiljde sig lite åt mellan länderna, men skillnaderna mellan länderna var större när det kom till dödstalet för äldre djur. Kilopriset för levande 
vikt är mycket högre för kultingar än för större djur, vilket gör att dödsfall senare i grisarnas liv inte är lika "dyra."

Den andel svinn av mjölk som presenteras i studien är enbart 0,33 \%, men statistik från Kokontrollen redovisar att 7 procent av den mjölk som produceras inte levereras till mejerierna. Förutsatt att proportionerna i studien stämmer skulle detta motsvara ett dubbelt så stort svinn som det som redovisas här.

Siffrorna för Global Warming Potentional av morötter reflekterar den svenska situationen där 5 procent är ekologiska och antas växa i torvjord. Samma situation antogs gälla i hela regionen. Detta betyder att siffrorna inte är representativa för all produktionsteknik som används, men då andelen ekologisk odling är liten tros denna osäkerhet vara liten.

Det är inte möjligt att undvika svinn helt och hållet. Detta är inte enbart "pengar som kastats i sjön." De experter och producenter vi har varit i kontakt med inom projektet betonar att det är omöjligt att helt eliminera svinn i primärproduktionen. Vi måste anta att ett visst svinn alltid kommer att finnas.

Möjligheterna att minska svinnet är heller inte lika stora för alla produktgrupper. Faktum är att mycket kraft läggs på att reducera svinn på grund av den ekonomiska förlust det innebär för producenterna. För vissa produkter kan det vara svårt att reducera svinnet ytterligare, men för andra är lättare. Det är troligtvis lättare att minska svinnet hos grönsaker, där svinnet ofta beror på avvikande storlek eller form, än vad det är för svinn av mjölk och kött. Där beror svinnet ofta på grund av sjukdomar som delvis ligger utanför producentens kontroll. Trots att möjligheterna att minska svinnet kan vara små ska de inte förringas. Även en liten minskning av svinn i djurproduktionen kan t.ex. ge stora effekter ur ett klimatperspektiv. 



\section{Fortsatt arbete}

Det finns ett stort behov av fortsatt arbete inom området. Detta kan delas in i tre olika områden: fortsatta studier, information och innovation.

\subsection{Fortsatta studier}

För att få en mer heltäckande bild av svinnet i primärproduktionen behövs fortsatta studier i form av fortsatt kartläggning av svinnet och analyser av vilka regelverk som påverkar svinnet. Även fortsatt forskning behövs för att öka kunskapen om odling, bättre sorter och hur vi i framtiden anpassar odlingen efter ett förändrat klimat.

\subsubsection{Fortsatt kartläggning}

Följande kartläggningar behövs för att få en bättre bild av hur stort problemet med svinn från primärproduktion i Norden är och orsakerna till detta:

- Datainsamling och kartläggning av svinnet från fler produktgrupper inklusive analyser av resultaten.

- Insamling av data från fler källor inom en och samma produktgrupp för att få bättre data.

- Mer noggrann genomgång av hur svinnet skiljer sig mellan de nordiska länderna för de studerade produkterna.

- Djupare studie av orsaker till att svinn uppstår för olika produkter.

\subsubsection{Regelverk}

Flera intressanta studier kring regelverk och deras påverkan på matsvinn skulle kunna göras:

- Myndigheterna förvaltar idag lagstiftning kring animaliska biprodukter samt foderfrågor. Vi har idag liten kunskap kring i vilken mån denna lagstiftning kan hindra en resurseffektiv livsmedelskedja. Vi behöver därför utreda vilka sekundära effekter regelverk kring foder och biprodukter har samt därefter ta ställning till om regelverken är väl avvägda mellan olika samhällsintressen.

- Kvalitetskrav uppges i FAOs rapport som en betydande orsak till svinn i utvecklade länder. Handelsnormer har också nämnts som en orsak till 
svinn. Vi har lite kunskap kring hur dessa regelverk påverkar svinn i primärproduktion och kan inte göra uttalanden kring om de är ett problem eller inte, ur ett resurshushållningsperspektiv.

- En jämförelse mellan länder av konsumentval eller tolkningar och tillämpningar av EU:s regelverk skulle vara intressant att se. Under projektets gång har representanter för branschen i Norge indikerat att konsumenterna i Norge är mer petiga när de väljer grönsaker och frukt i butikerna jämfört med svenska konsumenter. Genom att genomföra en sådan studie kan vi dra erfarenhet av andras framgångssagor och missar.

\subsubsection{Forskning}

Val av sort kan påverka hur stort svinnet i odling blir. Följande forskningsområden lyftes fram i studien:

- Öka kunskapen om olika odlade sorter. Vad passar till vilken jord eller vilket klimat?

- Öka kunskapen om hur vi i framtiden kan anpassa odlingen efter ett förändrat klimat genom val av utrustning, optimal grödrotation m.m.

\subsection{Information}

Vi behöver sprida kunskap om hur vi kan minska svinnet hos primärproducenterna genom t.ex. rådgivning om optimerad odling, transport och lagring, men även hur konsumentens val av produkter påverkar primärproduktionen. Samarbete och kunskapsutbyte mellan producenter är också viktigt för spridning av information.

\section{Sprida kunskap}

- Sprida kunskap om matproduktion och svinn och hur det hänger ihop.

- Informera konsumenterna om kosmetiska variationer på frukt och grönsaker som inte innebär skillnader för kvaliteten t.ex. slipsar på äpplen eller bruna prickar på bananer.

- Sprida kunskap om råvaror som inte utnyttjas till matproduktion i någon större utsträckning, t.ex. vissa sorts fisk som kommer upp som bifångst, vissa djurslag eller exotiska delar från djur.

- Sprida information om den arbets- och miljöinsats som krävs för att odla grönsaker eller föda upp djur. 


\section{Samarbete och kunskapsutbyte}

- Kunskaps- och erfarenhetsutbyte mellan lantbrukare med tips för hur man kan minska sitt svinn.

- Samarbete mellan lantbrukare för att hitta nya gemensamma lösningar till minskat svinn.

- Samarbete i hela livsmedelskedjan för att hitta vägar att minska svinnet i primärproduktionen.

\subsection{Innovation}

Nya innovativa produkter och affärsmodeller för att sälja produkter som annars skulle ha blivit ett svinn behöver tas fram.

\section{Innovativa produkter och försäljningskanaler}

- Nya produkter och recept som inspirerar till att använda råvaror som inte är så vanliga idag.

- Fler försäljningskanaler som t.ex. Bondens marknad, gårdsförsäljning eller direktförsäljning till restaurang eller butik.

\section{Nya affärsmodeller}

- Nya och bättre affärsmodeller för primärproducenterna.

- Ökad prisdifferenting för produkterna.

- Större storleks- och kvalitetsdifferentiering av produkterna. 



\section{Slutsatser}

Matsvinn är i denna studie definierat som " Mat som framställs i syfte att ätas av människor, men som av olika anledningar inte äts." Inom primärproduktionen förekommer också förluster i produktionen av mat. Vi väljer att använda begreppet svinn både för matsvinn och produktionsförluster i studien.

I den här studien har vi kartlagt svinn i primärproduktionen och analyserat konsekvenser av svinnet. En förenklad analys av orsaker till svinn, och möjlighetet för att minska svinnet har också gjorts.

Vi har sökt efter information om svinn i primärproduktionen i litteratur och statistiska databaser. Litteraturstudien visar att svinn av mat är ett stort problem i världen i dag. Undersökningar som har gjort visar att 30-50 \% av maten som produceres för humankonsumtion globalt sett inte äts. Vi kan konstatera att det har gjorts fler undersökningar i senare ledet av livsmedelskedjan än i de tidigare leden.

I den här studien har vi undersökt fem produkter i detalj. Svinnet var högt för grönsaker (morot $26 \%$, lök $13 \%$ ) och potatis (16 \%). För de animalska produkterna var svinnet inte lika högt (griskött $4 \%$ och mjölk $0,3 \%$ ). För mjölk blev en mindre del av värdekedjan undersökt jämfört med övriga produktgrupper, vilket delvis förklarar den låga siffran.

Konsekvenserna av svinnet är stort. Ca 45000 ton mat som var tänkt till humankonsumtion används på annat sätt eller går till avfallsbehandling. Värdet av detta svinn är ca 500 millioner Euro. Arealen som tas i anspråk för produktion av svinnet är ca 91000 hektar. Miljökonsekvenserna av svinnet är också stort. Klimagassutsläppen för produktion av svinnet är ca 386000 ton/år.

Nationell statistik fanns bara tillgänglig för griskött och för de andra produkterna hämtades data direkt från intervjuer med producenter, pakerier och andra aktörer. Data som hämtades in direkt baseras till stor del på uppskattningar.

Siffrorna är osäkra på grund av att underlaget är litet och att de i stor grad baseras på uppskattningar. Det finns också osäkerheter i metoden, bland annat har vi i denna studien använt siffror från ett land och applicerat detta på alla länder i undersökningen. Studien av svinn av griskött visar att variationen kan vara stor mellan länderna. Danmark har signifikant högre svinn av griskött än Norge och Sverige, men också signifkant högre produktion.

Genom fallstudierna kan vi konstatera att det finns potential att minska mängden svinn. Mycket av de förluster som uppstår i primärproduktionen är kopplade till produktion och lagring. De kan lättast 
åtgärdas genom att företagaren får bra rådgivning. Forskning för effektiv produktion sker idag, men det behövs även fungerande samarbeten mellan rådgivningsorganisationer och forskare.

Något som har varit påtagligt under studien är hur mycket förluster och svinn som är kopplat till konsumentkrav, handelsnormer, oförutsägbar efterfrågan m.m. Här är det viktigt att hitta former för att få ned svinnet tillsammans med representanter från hela livsmedelskedjan. Det finns en stor potential att minska den här typen av svinn, framförallt kopplat till frukt och grönt.

Det bör göras fler studier av svinn i primärproduktionen som omfattar fler produkter och en mer grundlig inhämtning av data. Inhämtningen av data bör också kvalitetssäkras. Orsaker och konsekvenser av svinnet bör utredas mer i detalj lika väl som möjliga åtgärder för att minska svinnet och effekten av dessa. 


\section{Referenslista}

(2011). Maten och miljön - Livscykelanalys av sju livsmedel. Stockholm: LRF.

Andresen, N. (den 6 September 2012). Referensgruppsmöte Matsvinn. (E. Einarson, Intervjuare)

Bengtsson, G. B., Sørensen, T., Martinsen, B. K., \& Tandberg, A. (1996). Svinnet på et utvalg ferske vegetabilier i Norge 1994-95. Sammendrag av resultater fra undersøkelsen. Oslo: Matforsk.

Bergman, A. (2012). Människan, kalven eller gödselbrunnen? Mjölkens destination och fördelning hos mjölkbonden. Växjö: Linnéuniversitetet.

Börjesson, L.-O. (November 2012). Äppelriket. (D. Persson, Intervjuare)

Cederberg, C., Sonesson, U., Henriksson, M., Davis, J., \& V, S. (2009). Greenhousegas emissions from production of meat, milk and eggs in Sweden 1990 and 2005.

Göteborg: SIK rapport 792, SIK- Institutet för Livsmedel och Bioteknik, ISBN 79891-7290-284-8.

Davis, J., M, W., V, S., A, E., Cederberg, C., \& Sonesson, U. (2011). Emissions of Greenhouse Gases from Production of Horticultural Products- Analysis of 17 products cultivated in Sweden. Göteborg: SIK- The Swedish Institute for Food and Biotechnology.

Donis Maria e-post. (2012). (D. Persson, Intervjuare)

Engstedt, M. (November 2012). Länsstyrelsen i Jönköpings län. (D. Persson, Intervjuare)

Europa kommissionen. (13 juni 2012). Commission Proposal COM(2011) 425 final. Bryssel: Europa kommissionen.

FAO. (2011). Global Food Losses and Food Waste - extent, causes and prevention. Rome: Food and Agriculture Organization of the United Nations.

FHL. (2011). Mljörapport 2010- tall og fakta fra norsk havbruksnaering. Oslo: FHL, Fiskeri och havsbruksnaeringens landsforening.

Fiskeridirektoratet. (den 3101 2013). Laks, regnbueorret og orret. Hämtat från www.fiskeridir.no: http://www.fiskeridir.no/statistikk/akvakultur/statistikk-forakvakultur/laks-regnbueoerret-og-oerret den 13022013

Fox, T. (2013). Global Food Waste Not Want Not. Storbritannien: Institution of mechanical Engineers (IMECHE).

Gustavsson, J. (2010). The Climate Change Impact of Retail Waste from Horticultural Products. Göteborg: SIK.

Gustavsson, J., Cederberg, C., Sonesson, U., \& Emanuelsson, A. (2013). The Methodology of the FAO study: "Global Food Losses and Food Waste-extent, causes and prevention"-FAO, 2011. Göteborg: SIK- Swedish Institute for Fodd and Biothechnology, SIK report No.857.

Gåle Gunilla e-post. (den 2 juli 2012). Kassation 2011. (H. Kättström, Intervjuare)

Hobson, R., \& Bruce, D. (2002). PM-Power and machinery: Seed Loss when Cutting a Standing Crop of Oilseed Rape with Two Types of Combine Harvestrer header. Biosystems Engineering vol 81 (3), ss. 281-286.

Hogstadius, C. (November 2012). Biskopsberga Jordgubbar. (D. Persson, Intervjuare) Hollstedt, S. (2011). Äggkvalitet kopplat till produktion, ekonomi och djurvälfärd hos svenska värphöns. Uppsala: Examensarbete 30 p, SLU, Institiutionen för husdjurens utfodring och vård.

Holstmark, K. (den 6 September 2012). Referensgruppsmöte Matsvinn. (E. Einarson, Intervjuare) 
Höglund, J. (2010). Hur kan man få ned dödligheten hos kalvarna i

dikobesättningarna? Alnarp: SLU, Fakulteten för Landskapslanering, trädgårds- och jordbruksvetenskap.

Jensen, C., Stenmarck, Å., Sörme, L., \& Dunsö, O. (2011). Matavfall 2010 från jord till bord - SMED. Norrköping: Sveriges Meteorologiska och Hydrologiska Institut.

Johansson, K. (den 6 September 2012). Referensgruppsmöte Matsvinn. (E. Einarson, Intervjuare)

Jordbruksverket. (2006). Metodbeskrivning EAA Ekonomisk kalkyl för jordbrukssektorn. Jönköping: Sveriges officiella statistik, Jordbruksverket.

Jordbruksverket. (2009). Ekonomi-Kalkyler för odling av grönsaker på friland, Jordbruksinformation 25. Jönköping: Ascard, J; Håkansson, B; Söderlind, M .

Jordbruksverket. (2010). Ekonomi i fruktodling- Kalkyler för äpple. . Jordbruksinformation 2010:5.

Jordbruksverket. (2012). Eu:s fiskerireform och WTO-förhandlingarna. Jönköping: Burman, C.; Johansson, K.; F., Palm; Matsson, Y.; Willhelmsson, M.; J., Kasteng, Rapport 2012:8 (s.15-17).

Jordbruksverket. (2012). Nötkreatursektorns uppbyggnad- En analys av struktur och slakt i nötkreatursektorn. Jönköping: Jordbruksverket, Statistikrapport 2012:03.

Jordbruksverket. (2012). Trädgårdsproduktion 2011- J0 33 SM 1201, korrigerad version 2012-09-03. Jönköping: Jordbruksverket- Sveriges oficiella staistik.

Jordbruksverkets statistikdatabas. (2012). Slakt av fjäderfä vid slakteri år 20052011, Sveriges officiella statistik. Hämtat från www.jordbruksverket.se: http://statistik.sjv.se den 8 februari 2013

Kelleher, K. (2005). Discard in the world's marine fisheries. Rom: FAO, Food and Agriculture Organisation of the United Nations.

Knowels, T. (1998). A review of the road transport of slaugther sheep. Veterinary Record 143, 212-219.

Kock, E., \& Andersson, J. (2012). Nyttan av att minska matsvinnet. Stockholm: Naturvårdsverket.

Ländell, G., \& Wahlstedt, G. (den 6 november 2012). Svinn inom primärproduktionen, mail konversation. (D. Persson, Intervjuare)

Malena, M., \& Voslarova, E. (2007). Comparison of mortality rates in different categories of pigs and cattle during transport for slaughter. ACTA VET 76, 109-116.

McConnel, C., Lombard, J., Wagner, B., \& Garry, F. (2008). Evaluation of factors assosiated woth increased dairy cow martality on United States dairy operations. Journal of Dairy Science vol91 (4), 1423-1432.

Nyemad, M. (2012). Nötkreatursektorns uppbyggnad- En analys av struktur och slakt i nötkreatursektorn. Jönköping: Jordbruksverket, Statistikrapport 2012:03.

Olofsson, M., \& Öhman, D. (2011). Matens pris . Tyskland: Reporto förlag AB.

Röös, E., Sundberg, C., \& Hansson, P.-A. (2010). Uncertainties in the carbon footprint of food products: a case study on table potatoes. Uppsala: SLU.

SCB. (1993). De objektiva skördeuppskattningarna 1993 omfattning och metoder. SCB, Statistiska centralbyrån.

Skontorp Honges, E., Ziegler, F., \& Sund, V. (2011). Carbon footpront and area use of farmed Norwegian salmon. Trondheim: SINTEF Fischeries and aquaculture.

Sköld, M. (den 6 September 2012). Referensgruppsmöte Matsvinn. (E. Einarson, Intervjuare)

Smil, V. (1 2004). Improving Efiiciency and Reducing Waste in Our Food System. Environmental Sciences, ss. 17-26.

Stenberg H. (den 22 juni 2010). Varför dör kalven? Hämtat från www.taurus.mu: www.taurus.mu den 8 februari 2013

Sällvik, K., Palmén, C., Bäcklund, N., \& Bostad, E. (2007). Transport av slaktkyckling från gård till slakteri- studier av klimat och analys av dödlighet- förslag till 
förbättringar. Alnarp: SLU, Fakulteten för landskapsplanering, trädgårds- och jordbruksvetenskap.

Tekniskt Ukeblad, T. (den 2012 januari 2012). Vi produserer 200 kilo laks per nordmann. Hämtat från tu.no/industri:

http://www.tu.no/industri/2012/01/30/vi-produserer-200-kilo-laks-pernordmann den 25 febrari 2013

Wallman, M., \& Sonesson, U. (2009). Life Cycle Assessment (LCA) of Swedish production of Turkey. Göteborg: SIK- The Swedish Intstitute for Food and Biotechnology.

Wallman, M., Cederberg, C., \& Sonesson, U. (2011). Life Cycle Assesment of Swedish Lamb Production. Göteborg: SIK The Swedish Institute for food and Biotechnology, SR 831, ISBN 978-917290-304-3.

Winter, C. (den 6 september 2012). Referensgruppsmöte Matsvinn. (E. Einarson, Intervjuare) 



\section{Summary}

Food loss and food waste occurs in the whole food supply chain, from production to consumer. Reliable data are lacking on losses and waste in primary production. In this study we have identified losses in primary production and analysed the consequences. Simplified analyses of the causes of wastage and of possibilities to reduce waste have also been made.

Food waste in this study is defined as "food that is meant to be eaten by humans but is not eaten for various reasons." Food waste in primary production is post-harvest plants or plant parts and animal products after slaughter or capture. When producing food, production losses also occur. In this study we choose word wastage which includes both food waste and production losses.

The majority of wastage in livestock production is animals that die on the farm. Wastage in aquaculture is mostly fish that die in the fish farm. In commercial fishing wastage is primarily discards due to quotas and size limits. Wastage in crop production and horticulture is mainly losses at harvest, quality changes during storage and selection criteria for size and shape and cosmetically defects.

A data collection was made for five items, carrot, potato, onion, milk and pork and they have been studied in more detail. Wastage rates were high for vegetables (carrot $26 \%$ and onion 13\%) and potatoes (16\%). For animal products wastage rates were not as high (pork $4 \%$ and milk $0.3 \%$ ). For milk a smaller part of the food chain was investigated compared to the other items, which partly explains the low percentage.

The effect of the wastage in this survey is large. About 45,000 tonnes of food that was meant for human consumption is used differently or becomes waste. The value of this wastage is about 500 million euros. The area used for the production of this waste is about 91,000 hectares. The environmental impact of the wastage is also large. This production of wastage contributes to greenhouse gas emissions of about 386,000 tonnes/year. The negative impact is larger for milk and pork production although even if the wastage rates are higher for carrots, onions and potatoes.

Within these case studies, we found a potential to reduce the amount of wastage. A lot of the wastage in primary production is linked to the production and storage. Research for efficient production as well as collaboration between researchers and advisory organisations is very important.

During the study it became clear that a large amount of wastage that occurs is linked to quality requirements and food standards, unpredictable requests etc. It is therefore important to find ways for wastage reduction together with representatives from the whole food supply chain. 
There is a large potential to reduce this type of wastage, especially when it comes to fruit and vegetables.

There is a potential to reduce wastage in primary production, but it is unreasonable to believe that it can be reduced to zero. In other words, we must expect wastage to some extent even in the future. 


\section{Appendix Norway "food waste" in the primary production of carrots and onions}

Erik Svanes, Department of Food and Packaging, Østfoldforskning.

\subsection{Introduction}

This appendix contains the study conducted in Norway about primary production of carrots and onions.

\subsubsection{Definition of food waste}

The study was based on the following definition of food waste: Food that is produced with the intention of being used for human consumption, but for different reasons is not being used for this purpose.

This definition is very different from the normal conception of waste, i.e. for household waste. The most common characteristic of this waste is that it is landfilled, incinerated or recycled. What is termed food waste in this report is a lot larger category than what is regularly seen as waste. In fact very little of the vegetable waste in Norway is sent to landfilling, incineration or recycling.

In a study by FAO (FAO, 2011) the definition is similar, but the semantic is different. The study distinguishes between food losses and food waste. The study states: "Food losses refer to a decrease in food quantity or quality in the early stages of the food supply chain, before the food products reach their final stage, reducing the amount of food suitable for human consumption."

Food waste on the other hand refers to the discarding of food products that are fit for consumption or fit to proceed in the food supply chain. This mostly occurs at later stages of the food supply chain, such as retail and consumer households."

\subsubsection{Quality loss}

Another related issue is quality loss, i.e. food that is intended for a certain usage (e.g. sold in retail to consumers), but is instead used for other uses which fetch a lower price, e.g. for use in frozen vegetable products. This was not the topic of this study but it was briefly covered in the 
study. The reason was that it is a closely related topic, it is regarded as very important by the primary producers and it is

\subsubsection{System boundaries}

Primary production in the case of vegetables can be interpreted in many ways. However, in the case of carrots in Norway, part of the product is stored on-farm, the rest in packing plants. For onion it is customary to store on-farm. Another complicating factor is that there is, in most cases, no sorting taking place between harvest and processing. This means that there is no way we can distinguish between waste occurring at the farm, in transport to processing, during storage and during processing.

In the FAO report (FAO, 2011) the food supply chain is divided into 5 parts, as shown in figure 1 . In the figure the steps that are included as primary production in this study is marked with yellow.

Figure 8. Comparison of system boundaries with FAO study

\begin{tabular}{|l|l|l|l|l|l|}
\hline FAO & $\begin{array}{l}\text { Agricultural } \\
\text { production }\end{array}$ & $\begin{array}{l}\text { Postharvest } \\
\text { handling and } \\
\text { storage }\end{array}$ & $\begin{array}{l}\text { Processing and } \\
\text { packaging }\end{array}$ & Distribution & $\begin{array}{l}\text { Consumpti- } \\
\text { on }\end{array}$ \\
\hline Interpretation & $\begin{array}{l}\text { Harvesting and } \\
\text { post-harvest } \\
\text { sorting }\end{array}$ & $\begin{array}{l}\text { Sorted out } \\
\text { during handling, } \\
\text { storage and } \\
\text { transport farm- } \\
\text { distribution. }\end{array}$ & $\begin{array}{l}\text { Sorted out just } \\
\text { before or during } \\
\text { processing and } \\
\text { packaging. }\end{array}$ & $\begin{array}{l}\text { Wholesale, } \\
\text { retail, trans- } \\
\text { ports. }\end{array}$ & $\begin{array}{l}\text { Loss in } \\
\text { households. }\end{array}$ \\
\hline This study & $\begin{array}{l}\text { Waste record- } \\
\text { ed in included, } \\
\text { no post-harvest } \\
\text { sorting done }\end{array}$ & $\begin{array}{l}\text { No sorting done } \\
\text { at this stage. }\end{array}$ & $\begin{array}{l}\text { Sorting is done } \\
\text { during pro- } \\
\text { cessing. }\end{array}$ & $\begin{array}{l}\text { Outside of } \\
\text { scope. }\end{array}$ & $\begin{array}{l}\text { Outside of } \\
\text { scope. }\end{array}$ \\
\hline
\end{tabular}

\subsection{Previous studies}

The study started with a search for information about food wastage for vegetables in Norway. National statistics, scientific literature and other sources were checked for information on this topic. One of the major information sources for information on yields, production area and other agriculture statistics is "Totalkalkylen for jordbruket," a publication that is published every year.

The only written information that was found on this subject was the study performed by Bengtsson et al in 1994-95. From other projects such as KLIMAT and Økofrukt the experience was that the actors involved did not have exact figures on the amount of food waste. Hence it would have been preferable to include measurements in the fields as the main methodology. However the budget did not allow such investigations to be made.

The major source of information was assumed to be the primary producers themselves, and operators of processing plants. Hence it was decided to collect information using phone interviews of these actors. 
FAO (Gustavsson et al 2013) has collected data and made estimations on food loss and food waste in a number of countries around the world. The numbers on vegetables waste at farm were primary (site-specific) data from a Swedish study: Davis et al (2011). This study found a wastage rate of $25 \%$ for carrots and $16 \%$ for onions based on data from a few large producers who answered questionnaires. The numbers for postharvest handling and storage came from FAO and the numbers for processing came from a European source, AWARENET in 2003 and are thus not specific for carrots and onions (all vegetables and fruits) and not for the Nordic Countries (the whole world or the whole of Europe).

\subsection{Method}

Interviews were made of 7 carrot producers and representative of 1 carrot packing plant. From another project information about yields and losses had been collected from 13 producers and 1 packing plant. Information of carrot waste in one packing plant was found on an Internet page based on a radio interview.

Interviews were made of 6 onion producers and 2 onion packing plants.

Carrots and onions are produced in a large number of producers in Norway. The main growing areas are Vestfold County, the area around lake Mjøsa, Østfold County, Rogaland County and areas in Sør- and NordTrøndelag Counties. Data was collected from all this areas.

The producers were picked based on their membership in the organisation "Grøntprodusentenes Samarbeidsråd" "(Vegetable and fruit producers cooperation Agency)." The representativity of these producers relative to the entire Norwegian production is not known. Interviews revealed that these producers are large scale producers. Hence the large amount of small scale producers in Norway is not represented in this study.

Time-related representativity was ensured by asking the producers for long time averages rather than just experiences this year.

The producers were asked questions about:

- The amount of product left in the field.

- The reasons for this "field waste."

- Whether storage, drying (only onion) and packing is done on-farm or in a separate packing plant.

- The amount of product harvested that is used for other purposes than human consumption.

- The reasons for this "storage waste."

- How the waste is used or treated.

- Improvement possibilities.

- Other information: Crop rotation, cultivar, type of storage. 


\subsection{Results}

\subsubsection{Carrot}

\section{Results from previous studies}

In the large study of Bengtsson et al (1995), the waste of carrots was found to be in the area of $25-30 \%$. The main causes for vegetable waste in general were rot and removal of damaged parts. It is assumed that removal of damaged parts was not done for vegetables but mostly for products like lettuce where such removal is easy to do. The variation is wastage was large, from 0 to $60 \%$. Waste in the field was not estimated in the survey.

In the study referred by Hille 19983 single trials and two trial series showed losses between $8 \%$ and $80 \%$ after storage for 8 months. The worst results were found for machine harvested carrot. For manually harvested carrot none of the trials showed more than 36\% loss, even after 7 months storage. The report concluded with an average of $40 \%$ waste after 7-8 months storage.

Davis et al (2011) recorded a wastage rate for the agriculture stage (see figure 1) of $25 \%$ for carrots and $16 \%$ for onions based on data from a few large Swedish producers who answered questionnaires.

\section{Results from KLIMAT}

From the KLIMAT project data from 13 producers in Lågendalen, an area in Vestfold County in South-Eastern Norway had shown that slightly less than $50 \%$ of the harvested product was packed and sold to retail or large kitchens (institutions, hospitals, schools, prisons, etc). A large part of the product not used for these purposes was sold to industry for use in e.g. frozen vegetable products, but the exact amount was not known. The remaining product was sold as animal feed, either to cows or to wild animals. The packing plant reported an estimated 4-5\% evaporation loss. Furthermore the packing plant observed that some products rots completely to earth and is collected together with earth washed of the products, but the amount of this fraction could not be determined.

\section{Results from present study}

Amount of waste. None of the producers asked in the current study had measured the amount of carrot waste. They estimated the amount harvested by multiplying the amount of bins with the approximate holding capacity of the bins. The amount lost was the difference between this amount and the amount they could sell.

Estimates of field waste was said to be very uncertain. Of the six answers, one said that nothing remained, one said $800-1000 \mathrm{~kg}$ pr ha remained, the remaining gave answers between 0,5 and $2-3 \%$. The arithmetic mean of these figures was $1,6 \%$ but the informants said that estimates were very unsure. 
The respondents estimated storage waste in the range from 10 to $40 \%$. 4 respondents reported the waste in intervals, one reported a single number but said the result was very uncertain. When data was given as intervals, the average of the interval was used in the calculations. One respondent who reported a waste of $40 \%$ was not sure if the number also included carrot going to industrial uses, e.g. frozen vegetables for human consumption. Had the wastage rate for this producer been $30 \%$ the overall average storage waste would have been $24 \%$. The storage waste was found to be $25 \%$, calculated as the average of all 8 respondents.

The field waste was $1.6 \%$

The storage waste was $25 \%$

\section{Reasons for waste}

The main reasons behind the waste were wrong size and shape and spots and miscolouring. The wrong size products were either too big or too small, but too large products are normally used by large kitchens. It is typically the too small products that are classified as food waste. The wrong shape products are typically double root products. Two respondents said that one of the four leading retail chains in Norway accepts small size and wrong shape products in their cheap private-brand product. Spots and miscolouring can mean anything from small spots that has no effect on taste, to large rotten areas. The main reason was reported to be crop diseases.

Other prominent reasons were mechanical damage and cracks. Mechanical damage happens during harvesting and subsequent handling of the products. Cracks occur during growing and are largely the result of climatic conditions.

The respondents could not quantify the amount of product lost due to each of the noted reasons.

\section{Treatment of waste}

All respondents said that the waste was used for animal feed, mostly to cows. Only one producer received payment for the waste, the others gave it away for free on condition that the recipient did the transportation. One respondent said that it was valuable for him that the recipient would, whenever necessary, collect the waste.

One producer said that part of the waste was sold as feed to horses which gave a good price.

\section{Other factors}

All producers use crop rotation. One producer mentioned the skill of the producer as an important factor. One producer mentioned drainage of the fields and market acceptance for misshaped and under/over-size products as most important improvement possibilities. 


\subsubsection{Onion}

\section{Results from previous studies}

Bengtsson et al (1995) reported a producer`s onion wastage of $20-30 \%$. The variation between respondents was large, from 7 to $23 \%$.

The study referred by Hille 1998 found average losses of $24 \%$ and $34 \%$ after 8 months storage from two trial series at the University for Energy and Life Sciences. A storage trial of 9 different onion cultivars showed losses from 4 to $19 \%$ after 6 months storage. One trial in 1993 showed, however much higher losses: $38-65 \%$ after 9 months storage.

\section{The present study}

None of the producers could quantify field waste, except that it was very low, far less than $1 \%$.

The estimated storage waste in the range from 6.5 to $20 \%$. 4 respondents reported the waste in intervals. When data was given as intervals, the average of the interval was used in the calculations. The average waste was $13 \%$.

The field waste could not be qualified but was estimated as "far less than $1 \%$.

The average storage waste was $13 \%$.

\section{Reasons for waste}

The main reasons for the waste were rot, mechanical damage, small products and small imperfections such as skin discoloration. The predominant answer was rot. One producer said that damage from "onion fly" was a major contributor.

\section{Treatment of waste}

Onion waste cannot be used for animal feed. In most cases it is composted. If the composting cannot be done at the place of sorting (mostly packing plant) it must be delivered as "hazardous waste" which is a major cost for the producers.

\section{Other issues}

Major improvement possibilities are to sell products that are fit for consumption but not accepted by the retail chains. This concerns small products and products with cosmetic imperfections such as small spots or discolouring. The quality of the product can be improved by improved drying techniques and better storage temperature regulation. Drying should be done at as low temperature as possible. The products should be cooled, at least from March-April onwards. Most producers use the "summit" cultivar. Crop rotation is used by all producers. The respondents did not think that changes in crop rotation or cultivar could improve the waste situation significantly. 


\subsection{Discussion}

The results are very uncertain since no producers or packing plants seems to measure the waste. The numbers for field waste was more uncertain than the numbers for storage waste. All respondents reported large variations from year to year, mostly due to climatic conditions.

In this study interviews was the only method possible given restraints in time and resources. Measuring the amount of waste and dividing it according to the different waste reasons would give a much better picture of the wastage rate and the actual causes of this waste.

In the FAO study the term primary production is only used once and is not defined. In this study primary production is equalled to "agriculture." Thus, in this study it can be inferred that only the first Life Cycle Stage "agricultural production" should be called primary production. The data in this study did not allow distinguish between the categories used by FAO. In this study only field loss is recorded, not post-harvest sorting. This means that FAO numbers and numbers from this study are not comparable, a fact that is clearly reflected in the results: $1 ., 6 \%$ in this study compared to $25 \%$ of the Swedish study. The numbers are, however, comparable if one looks at the three first life cycle stages. FAO gets $32 \%$ for carrots $(25 \%$ agriculture, $5 \%$ post-harvest handling and storage, $2 \%$ processing and packaging), this study concludes $26.6 \%$ and the previous study by Bengtsson et al concludes 25-30\%. For onions the numbers are less similar, respectively: $23 \%, 14 \%$ and $20-30 \%$.

Based on experiences from this study we have reason to question the conclusion that the numbers recorded by FAO is "agricultural waste." The respondents in our study and in the Bengtsson study said that the newly harvested carrots had a very low wastage rate. In the FAO study the carrot waste is said to come from farms without storage. If this means that all the FAO waste comes from sorting of newly harvested carrots the wastage rate seems very high in comparison with the experiences from Norwegian producers in this study. There can be several explanations to the high Swedish number. One possible reason is that products of wrong shape and size and with small imperfections such as spots are included as waste. Such products are in Norway mostly not accepted by retail or it is only accepted by other users (e.g. frozen vegetable producers) for a low price. Another possible reason is that it is in fact the wastage rate after storage that is recorded.

Whatever the reason for the relative similarity in final numbers for the three first stages but discrepancy in numbers on the agriculture stage, the figures reveal two methodological problems: 
- The waste might be attributed to different life cycle stages because it is discovered in different parts of the value chain but does in fact appear in the same life cycle stages.

- Much of the waste that is identified as being attributable to agriculture might in reality be attributable to later stages such as retail or consumers because of the low level of tolerance that retailers/consumers have for products with deviating appearance such as size, shape and small imperfections such as spots.

\subsection{Conclusion}

Carrot and onion primary production waste can be classified as either field waste or storage waste. Field waste is what is left in the field, storage waste is the amount of product sorted out when processing.

- Carrots: Field waste was $1.6 \%$ of harvested amount, storage waste was $25 \%$ of the amount put into storage.

- Onion: Field waste was far less than $1 \%$ of harvested amount, storage waste was $13 \%$ of the amount put into storage.

- The main reason for waste was bad appearance caused by rot, other illnesses and non-optimal treatment. Another major reason was wrong size/shape.

- It is very difficult to reduce field waste. Storage waste can be reduced by finding markets for "wrong" size and shape products, reducing the incidence of illnesses by various means and improving drying and storage conditions.

- It is not realistic to reduce the wastage rate to zero. Some waste is inevitable.

- Some of the waste recorded at the processing stage is probably caused by the agricultural stage, which makes it difficult to exactly quantify primary production waste. Thus the whole chain from farming to processing was regarded as primary production in this study.

- Some of the waste might be attributed to agriculture but is in fact caused by later stages such as retail or consumers because of these actors low tolerance for deviating appearance. Examples include small imperfections such as small spots or deviating shape which is still fit for human consumption but is instead e.g. fed to animals or composted. 


\subsection{References}

Bengtsson GB, Sørensen T, Martinsen BK og Tandberg A: Svinn på et utvalg av ferske vegetabilier i Norge 1994-95. Sammendrag av resultater fra undersøkelsen. (In Norwegian). Nofima Matforsk 1995.

Davis J, Wallmann M, Sund V, Emanuelsson A, Cederberg C, og Sonesson U. Emissions of Greenhours Gases from Production of Horticultural Products. SIK, June 2011.

FAO. (2011). Global Food Losses and Food Waste - extent, causes and prevention. Rome: Food and Agriculture Organization of the United Nations.

Gustavsson J, Cederberg C, Sonesson U, og Emanuelsson A. The Metodology of the FAO study: "Global Food Losses and Fooed Waste- extent, causes and prevention"FAO 2011. By SIK - The Swedish Institute for Food and Biotechnology., January 2013.

Hille, J: Godt norsk? CO2-utslipp ved produksjon, lagring og transport av norsk og importert frukt/grønnsaker (In Norwegian). Fremtiden i våre hender forskningsinstitutt. Rapport 7/1998.

NILF (2012): Totalkalkylen for Jordbruket. Jordbrukets totalregnskap 2010 og 2011. Budsjett 2012. www.nilf.no/...jordbruket/.../totalkalkylenpublikasjonen2012.pdf 



\section{Appendix Finland "food waste" during primary production of potato}

Hanna Hartikainen, Agrifood Research Finland, MTT

\subsection{Introduction}

\subsection{Potato farming in Finland}

In Finland the average annual volume of potato production is around 700 million kilos, but this varies between $+/-20 \%$. Half of the production is table potato and one sixth is used for processed potato products. Of the remainder, most is used for starch production. In total, 400-500 million kilos are aimed at human consumption (excluding seed potatoes and potatoes used for starch production - purposes other than for human consumption) (Matilda 2012; Tike 2010).

\subsubsection{Definition of food waste during primary production of potato and system boundaries}

In this study food waste during potato production was defined as potato produced for human consumption, but not ultimately consumed by humans. Thus, in this study potato intended to be consumed by humans but used as animal feed, for example, is considered to be waste. A study of FAO (Gustavsson et al 2013) gives same definition for food waste defining food waste/losses as food that could have been used for human consumption (food produced for human consumption). However, the FAO study distinguishes food waste from food losses. In the FAO study food losses is defined as "a decrease in food quantity or quality in the early stages of the food supply chain, before the food products reach their final stage," whilst, food waste refers to "the discarding of food products that are fit for consumption or fit to proceed in the food supply chain." As a difference to the FAO study, in this study the potato waste term refers to both potato losses and waste. This is because in some cases it is difficult, or frankly impossible, to clearly distinguish potato waste from potato losses.

The FAO study defines five steps of the food supply chain: agricultural production, postharvest handling and storage, processing and packaging, distribution, and consumption. In this study, the sorting and dam- 
age/spillage during harvest operation, which in the FAO study is defined as agricultural production, is considered, but also postharvest handling, sorting, storage and packing are included in this study. This is because quite often handling and storing of potato happens in farm site, and packing can happen in farm site or in a packing plant. Also, especially sorting of potato can happen in various steps, and thus it is difficult to distinguish it to one separate step. Moreover, if potato is rejected in retail/industry gate, and ends up as waste, it can be argued that it is waste of the previous actor which is often the farmer or the packer. All in all, in this study the potato waste during primary production is not only considered to be the potato left during lifting and sorting, but potato waste from handling, storing and packing is also considered.

Additionally, second-class potato, that is, potato that is used as human food but redirected to alternative uses for a lower price, for potato flake production, for example, is also briefly discussed in this study.

\subsubsection{Choice of study methods}

There is little research on food waste during primary production in Finland, and potato waste is not an exception. Additionally, field research is time demanding and a rather uncertain study method because of high annual variation in potato yields. Thus, the study methods chosen were a literature review and a questionnaire. The questionnaire was designed for some key Finnish stakeholders and, in total, five potato experts (researchers and advisors) and potato producers (farmers, packers and industry representatives) responded.

\subsection{Study methods}

\subsubsection{Literature review}

The literature review was undertaken mainly to get a better understanding of different potato production scenarios. Finnish potato production was mapped, i.e. different cultivation areas, potato varieties and uses were studied. Additionally, the existing statistics and literature on potato production and waste were studied to get a better picture of how much data is available on potato waste and to establish the most relevant questions for the questionnaire.

\subsubsection{Questionnaire}

A set of questions (Appendix 1) were formulated and addressed to potato experts (researchers and advisors) and potato producers (farmers, packers and industry representatives). In addition to the questionnaire 
some follow-up questions were also asked in a phone interview. Five experts and six potato producers participated in the study during the summer and fall of 2012. Of the six producers two were both farmers and packers and the rest were from the potato industry: three produced potato products (packed table potato/processed potato products) and one produced potato starch.

\subsection{Results}

\subsubsection{Waste percentage during primary production}

\section{Field waste}

According to one potato expert, in Finland $2-5 \%$ of potato is wasted during lifting and sorting. One farmer/packer estimated that the amount was as high as $5-15 \%$ on his own potato farm. Additionally, according to a recently completed Finnish questionnaire potato farmers estimated that $1-15 \%$ of the crop is left in the field - the average being around 5\% (Ahokas et al. 2012). Thus, while the average amount such potato waste is about $5 \%$, the variation can be quite high. One of the main reasons for such losses is that the potatoes are too small.

\section{After field waste}

According to the Finnish statistics (Matilda 2012), the average amount of table potato that does not reach its primary destination (retail, canteen or industry) is around $20 \%$. In answering the questionnaire one expert and one producer also claimed it to be around $20 \%$. Some of this table potato is redirected to alternative uses, for example to potato flake production, but in the questionnaire one industry representative and one expert estimated that around $10-15 \%$ of table potato is not directed to human consumption, and thus is considered here as potato waste. In the questionnaire of Ahokas et al. (2012), the potato packers (8) estimated that $10-17 \%$ of table potato is not sold for its primary use (Appendix 2). Moreover, the seed potato packers (14) estimated that $3-15 \%$ of seed potato is not sold for its primary use. However, according to Ahokas et al. (2012), in northern Ostrobothnia, around 85\% of this "second-class seed potato" is redirected to potato product processing. Altogether, these estimates indicate high levels of uncertainty for the table and seed potato waste that occur after potato lifting and before selling, the amount ranging between a few percent and 15 percent.

In starch production one industry representative estimated the rejection level to be $2 \%$ at most and one expert estimated it to be "a few percent." In further potato processing, one industry representative estimated that the industry rejects less than $5 \%$ of any batch. Overall, for potato 
processing (starch production and potato product processing) the rejection level was estimated to be only a few percent.

\subsubsection{Reasons for waste}

\section{Reasons for field waste}

One of the main reasons for potato waste during primary production is poor weather conditions; too much rain, too dry and/or too cold. Other reasons include incorrect fertilization, wrong soil type $(\mathrm{pH}$ and structure), wrong seeding density, and harsh handling. These factors can lead to infection, shape defects, poor growth, internal quality deficiency, blemishing, and low self life. It is also important to consider that many field practices, like rough lifting, which cause blemishing, can ultimately lead to potato waste.

According to a potato expert, too small potatoes do not differ in taste but nonetheless are usually considered to be second-class produce. Moreover, according to the questionnaire study of Ahokas et al. (2012), the majority opinion in the questionnaire was that it is not profitable to lift and sell potatoes that are too small. Small potatoes represent one of the major reasons for potato waste during primary production, although they can usually be lifted by adjusting the lifting machine settings.

\section{Reasons for after-field waste}

One important reason for after-field waste is inappropriate storage conditions, including wrong temperature, lack of sufficient oxygen and high moisture. Also, if potato is stored over-winter and conditions are kept optimal, the potato loses around 6-7\% of its weight through evaporation (expert), but in sub-optimal storage conditions the weight loss can reach even 20\% (farmer/packer).

Quality requirements are also important. In the retail/catering sector there are specific requirements regarding size (30-60 mm; 3 experts), uniformity of the batch (each batch has to contain potatoes of same size), and appearance (potato has to be free from bruises and scabs). Internal quality is also important. On the other hand, there are usually fewer requirements in industry regarding size and appearance, but this is highly dependent on the situation. For instance, some factories take only relatively large potatoes and some, such as the potato flake industry, take almost all type.

Potato yield varies in Finland and leads to overproduction once every 5-7 years. Due to high yields it is possible that some edible potatoes end up as waste. Also, poor logistics and poor structure of the markets may result in product loss - even when the yield is relatively low. The alternative uses of potato (potato flake, starch production etc.) depend on profit margins. For instance, nowadays starch producers can take increasing volumes for starch production, but if the starch recovery rate is 
not that good it can be too costly to use potatoes that have low starch content. Moreover, according to one expert, it is relatively easy to direct the surplus potato to an alternative use, e.g. to potato flake production, but the flake potato is usually sold for close to nothing, so there is little economic incentive to do so (industry representative). In some cases there could be an incentive if discard costs are high and if the sale price covers transportation costs (expert).

\section{Measures to reduce waste}

There are several possible means to reduce potato waste in primary production, including improved farming methods. For instance, farmers could improve crop rotation and take better care of soil structure. It would also be important to optimize the practices for different potato varieties. More gentle potato lifting and handling is important, which could be accomplished by investing in better lifting machinery.

Storage conditions could be improved by installing efficient air conditioning for example. It would also be best to store only good-quality potatoes and find uses for potatoes that have limited shelf lives due to blemishing. Regarding alternative uses for potatoes, one could learn from existing systems. For instance, centralized potato pick-up could reduce costs and ease the field-to-use process.

\subsection{Discussion}

The literature review and questionnaire were considered appropriate for this study because there were few data on the volumes of and reasons for potato waste during primary production. Additionally, field research is time consuming and is an uncertain study method given the high annual variation in potato yields.

There was substantial uncertainty in our questionnaire regarding amount of potato waste for three principal reasons. Firstly, we were able to interview only six potato production chain actors, who represented only a small fraction of Finnish potato producers. Luckily the questionnaire results from the study of Ahokas et al. (2012) gave us more farmer and packer estimations of their potato losses. Additionally, the five experts involved in our questionnaire gave us broader insight. Secondly, the field waste estimates were based on respondent estimations and not on actual measurements. Thirdly, there is considerable variation in practices and systems, and thus the results varied as well. 


\subsection{Conclusion}

The estimated $5 \%$ of potato lost during harvest and sorting is substantial. Even more is lost before the potato is sold. Many tonnes of potato are lost during storage and packing. Some of these potatoes, including second-class potatoes, are directed to alternative uses, but are usually sold for much less. Low profits reduce the use of the second-class potato.

In the future there will be need for a more in-depth study to get a better understanding of how much potato is lost in food supply chain and what the potential is to reduce potato waste. Also, a broader sample of potato producers would provide more reliable results and allow better tools to be developed to make improvements through, for example, comparing existing systems and establishing best practices and new ways to develop the systems.

\subsection{References}

Ahokas M., Välimaa A-L., Kankaala A., Lötjönen T., Virtanen E. (2012) Perunan ja vihannesten sivuvirtojen arvokomponenttien hyötykäyttö (In Finnish) Utilization of Byproducts from Potatoes and Vegetables for Value-Added Products, MTT Report 67.

FAO. (2011). Global Food Losses and Food Waste - extent, causes and prevention. Rome: Food and Agriculture Organization of the United Nations.

Gustavsson J, Cederberg C, Sonesson U, Emanuelsson A. The Metodology of the FAO study: "Global Food Losses and Fooed Waste- extent, causes and prevention" - FAO, 2011. SIK, January 2013.

Matilda (2012) Agricultural Statistics, http://www.maataloustilastot.fi/en

Tike (2010) Pellolta pöytään 2010 (In Finnish) From farm to fork 2010

\subsection{Appendix 1}

\section{The main questions:}

- What is the main reason for potato waste during primary production?

- Why is there product loss during primary production (besides due to plant diseases, pests and weather conditions)?

- In how many cases the potato does not meet the quality requirements set by retail sector and/or industry? Where does this potato go?

- How big impact storing has to potato waste/product loss? Is it possible to attain remarkable reductions in waste amounts/product loss via improved storing conditions?

- How the quality requirements vary in retail sector and in industry?

- Do good and bad years have an impact to the quality requirements? 
- Are there any differences between potato varieties? E.g. which varieties meet the quality requirements more often?

- Do geographical differences have an impact to the quality?

- How much of the potato is left to the potato field during harvesting?

- Does the size or/and the farm specialization have an impact to product loss?

- Is it always possible to find another use for extra potatoes or do these potatoes end up as waste?

- Are smaller/deformed potatoes different in taste? Is it beneficial to leave some of the potato to field?

\subsection{Appendix 2}

Harvest handling and effluents in table and see potato packing plants (edit. Ahonen et al. 2012)

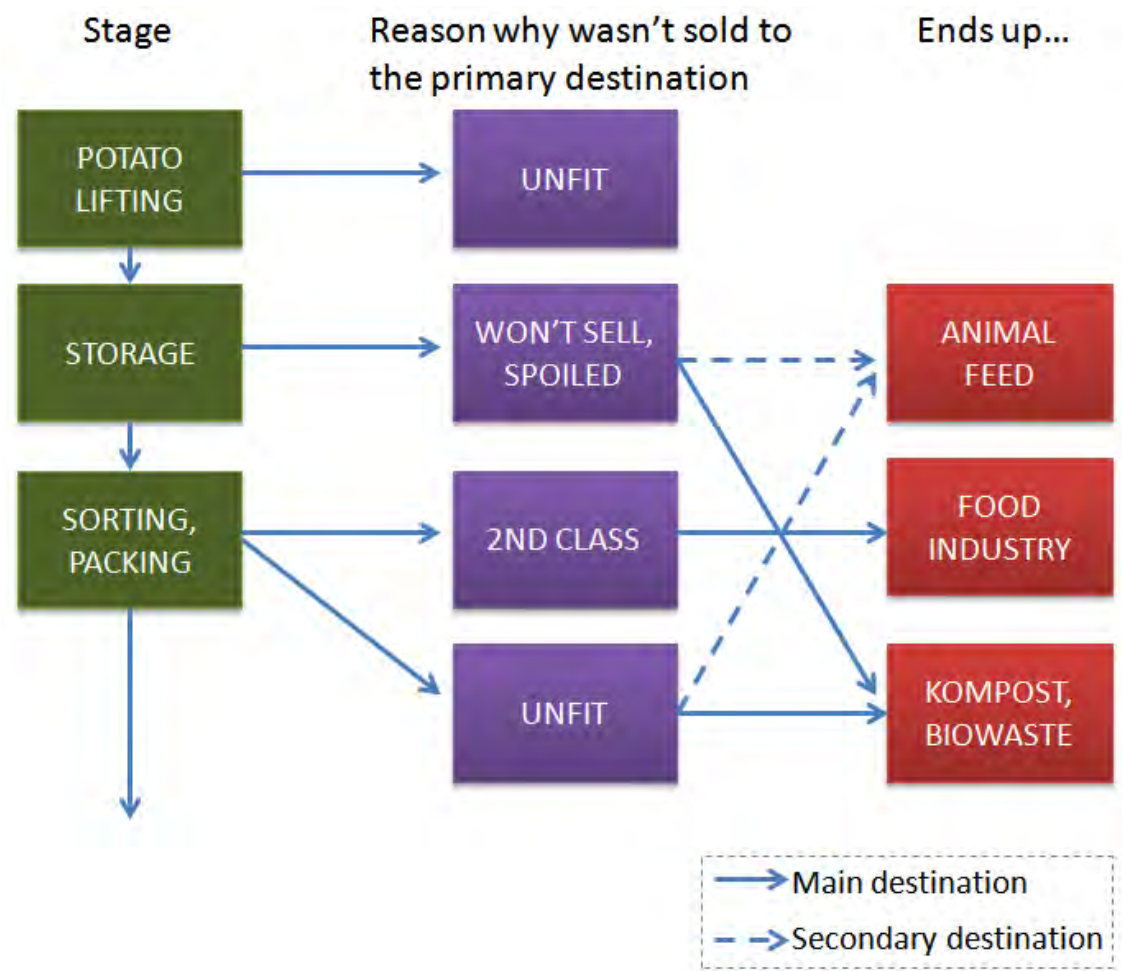





\section{Appendix Sweden "food waste" in primary production of milk}

Elin Einarson, Niels Andresen and Ulrika Franke, Swedish Board of Agriculture, Sweden.2013-01-16.

\subsection{Introduction}

This section on food waste in primary production of milk is based on Agneta Bergman's Bachelor thesis (reference), if nothing else is referred to.

\subsubsection{Definition of food waste generated in the primary production of milk}

Definition: Waste of milk, which has been produced and is intended for human consumption, but for different reasons, is not being used for this purpose.

The destination of milk on farms is either that it is sent to the dairy, used for human consumtion on the farm, given to the calves or thrown at the manure well. Assuming that milk used for the calves is unavoidable and a resource on the farm in producing new heifers and bulls, only milk destinated to the manure well is defined as food waste. Figure 1 shows the destination of milk at farms.

\subsubsection{System boundaries}

This study is limited to primary production of milk at the farm. The waste of milk is only studied between the dairy cow and delivering to the dairy industry. The losses related to feeding and handling of feed is not included, neither are the losses of milk after leaving the farm taken into account.

It can be discussed whether the losses related to feeding the cows and production of feed shall be included in the waste calculation. These losses will indirectly lead to less milk produced on the farm. In this study these losses are excluded. However, the size of these losses is discussed in chapter 4. 
Figure 1. The destination of milk at farms is either to the dairy, human consumtion on the farm, to the calves or to the manure well

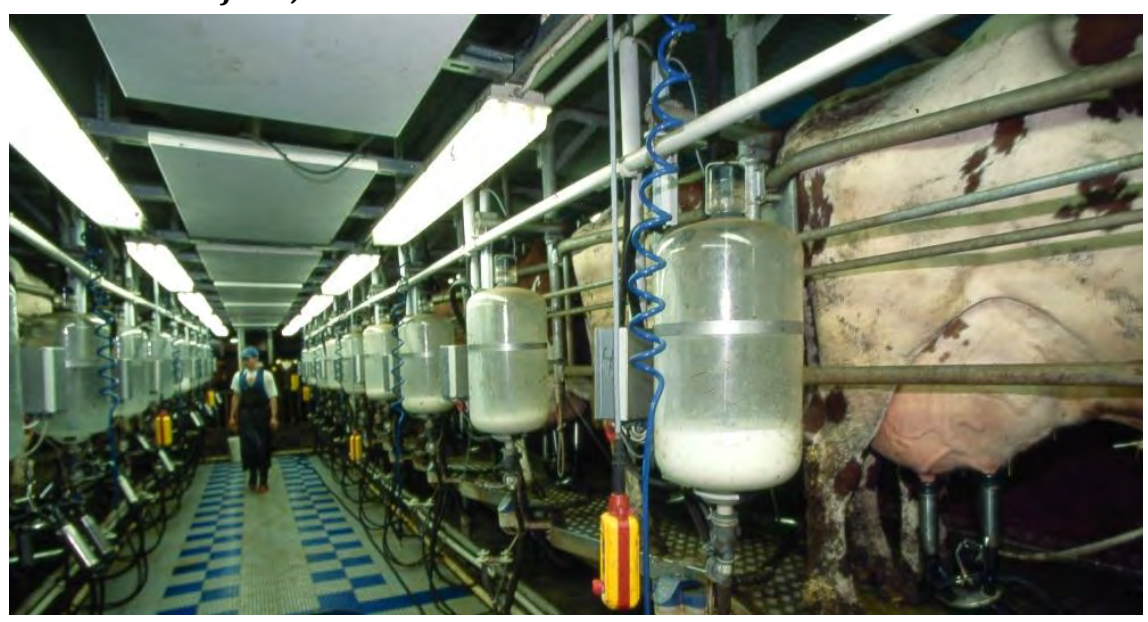

\subsubsection{Choice of method}

The method for estimating milk waste in primary production is based on interviews with 17 dairy farmers and complemented with data from the Swedish database for milk recording and litterature studies. The interviews were essential to get an understanding of how to interpret the data from the milk recording database, as quality of the reported data can vary.

\subsection{Method}

\subsubsection{Interviews}

Agneta Bergman made interviews with 17 dairy farmers during the spring 2012. All farmers were located within $120 \mathrm{~km}$ from Kungälv in the western part of Sweden, see Figure 2.

Figure 2 The red circle shows the region in Sweden where the interviewed farmers are locatad

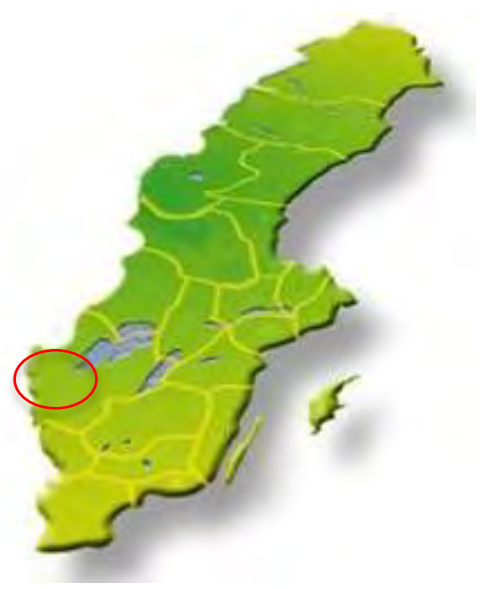


The study includes organic (KRAV) and conventional farms. Farms with traditional machine milking (TMMS) in a tied up system or in a milking parlor as well as farms with robot milking system, so called voluntary milking system (VMS) are included in the study. The selection of farms was made by recommendations mainly from other dairy farmers but also in collaboration with extension organizations. The time for each interview was approximately 1 hour. Table 1 below show the distribution in herd size, and production systems of the farms in the study.

Table 1 Number of interviewed farms divided into: Herd size, conventional or organic farms, robot milking system (VMS) or traditional machine milking system (TMMS)

\begin{tabular}{llll}
\hline $\begin{array}{l}\text { Herd size } \\
\text { (number of cows) }\end{array}$ & $\begin{array}{l}\text { Number of farms } \\
\text { within each herd } \\
\text { size }\end{array}$ & $\begin{array}{l}\text { Number of conventional/ } \\
\text { organic (KRAV) farms }\end{array}$ & $\begin{array}{l}\text { Number of farms with robot- } \\
\text { (VMS)/traditional machine } \\
\text { milking (TMMS) - }\end{array}$ \\
\hline $16-38$ & 4 & 4 Conventional & 4 TMMS \\
$39-50$ & 4 & 3 Conventional 1 organic & 4 TMMS \\
$51-66$ & 3 & 1 Conventional 2 organic & 1 VMS 2 TMMS \\
$67-120$ & 3 & 3 Conventional & VMS 2 TMMS \\
$121-160$ & 3 & 3 Conventional & \\
\hline
\end{tabular}

The interviews were based on following questions:

- Number of calves borned during 2011

- kg milk consumed by each calf

- How is antibiotic contaminated milk handled

- The most commom treatment period for antibiotics

- The most common withdrawal period

- How much milk is used within the household at the farm

- How much milk is sold directly to consumers from the farm

- Other reasons for the milk not being sold to the dairy

- Are there any laws, rules or other requirements that affects the wasteage of milk

\subsubsection{Milk Recording}

In order to get data of produced and sold milk from the farms the database for milk recording was used.

The Swedish Dairy Association is responsible for the database and $85 \%$ of all Swedish dairy farms are members of the system. The database is used for guidance, statistics and research.

Data from the milk recording system used in this study are: 
- average number of cows/12 months

- average produced milk in kg ECM2/cow during 12 months

- diseases, treated with penicillin

- produced milk from penicillin treated cows in $\mathrm{kg}$

ECM/outbreak of a disease.

\subsubsection{Time period and geographical area}

The interviews were made in spring 2012 and all data on milk production and cows, calves etc is from the 12 month period prior to that.

This study only includes waste of milk from the udder of the cow to delivery to the dairy. The varition is estimated to be low and is due to any local differences in production conditions. We therefore assume that the results are applicable for the rest of Sweden.

\subsection{Results}

\subsubsection{Food waste in percent}

The distribution of milk delivered to the dairy, consumed by humans at the farm, consumed by the calfes or thrown in the manure well is shown in Figure 3 below.

Figure 3 Destination of the milk at the farm. About 97 percent of the produced milk is delivered to the dairy, 2,5 percent are consumed by the calves, 0,30 percent used for human consumtion at the farm and 0,32 percent is thrown in the manure well

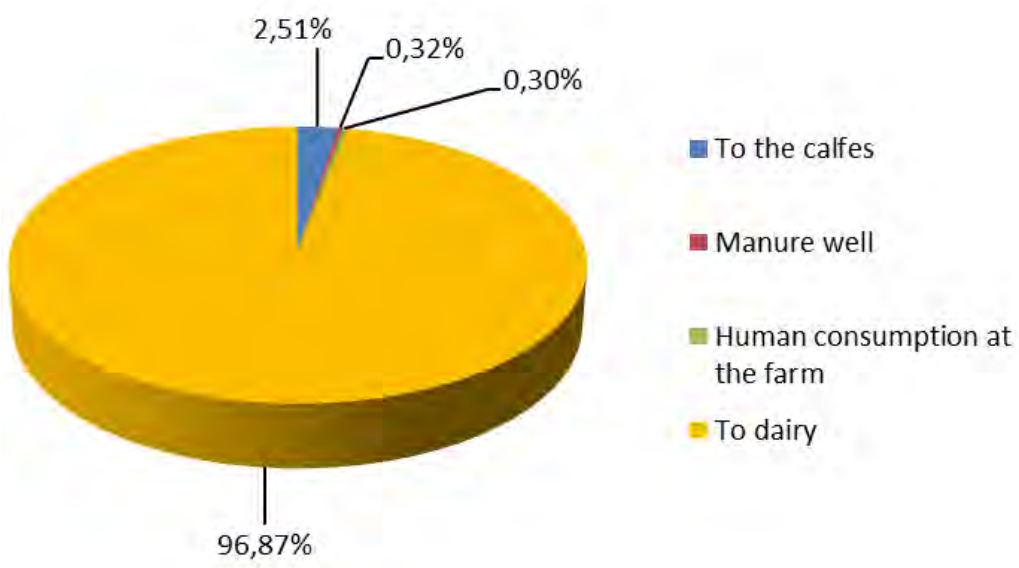

22 ECM: Energy Corrected Milk 
Defining the milk waste only as milk thrown in the manure well gives a very small percentage of milk waste. Although, if scaled up to the whole nation, the total amount of waste is large. The total production of milk in Sweden 2011 was 2850000 tons of milk. This means that the total waste is 9120 tons. This figure might be underestimated considering the uncertainty on how much milk is really sent to the dairy, see chapter 4 .

\subsubsection{Reasons behind milk waste}

The main cause for wasting milk is penicillin treatment, due to mastitis. Other reasons for milk waste are diseases on the cows that cause poor milk quality, problems with the cooling system in the milk tank, and milk stuck in the tank filter, etc. However, these problems are considered to be very small.

\subsubsection{Measures to reduce waste}

The interviewed farmers seem to have different attitudes on the handling of penicillin treated milk. Three of the farmers are not treating the cows with penicillin at all. Three farmers consequently throw the treated milk in the manure well. Two gave the milk to the calves, three gave the milk to the bull calves and four throw the milk in the manure well during the treatment period and gave it to the calves during the withdrawal period.

The organic farms have double withdrawal period compared to conventional farms. During the second withdrawal period it is allowed to use the milk to the calves. One farm gave this milk to the bull calves and one farm to all calves.

The best way to reduce waste of milk is to have a good health status in the herd in order to reduce the amount of penicillin treated milk. 52 percent of the penicillin treated milk is thrown in the manure well (see Figure 4) and 48 percent is given to calves. There is one on-going study at the Swedish University of Agricultural Sciences (SLU), studying the effects and consequences of feeding penicillin treated milk to calves. Results from this study will be very interesting to follow. Feeding calves with antibiotic contaminated milk is very problematic due to resistance for penicillin treatment later on in the calves' life. Many veterinarians and doctors within the human sector see big problems with circulating antibiotics in healthy animals. However, giving milk from the withdrawal period to the calves could be one way to reduce milk waste. 
Figure 4 the amount of penicillin treated milk destinated to the calves and to the manure well

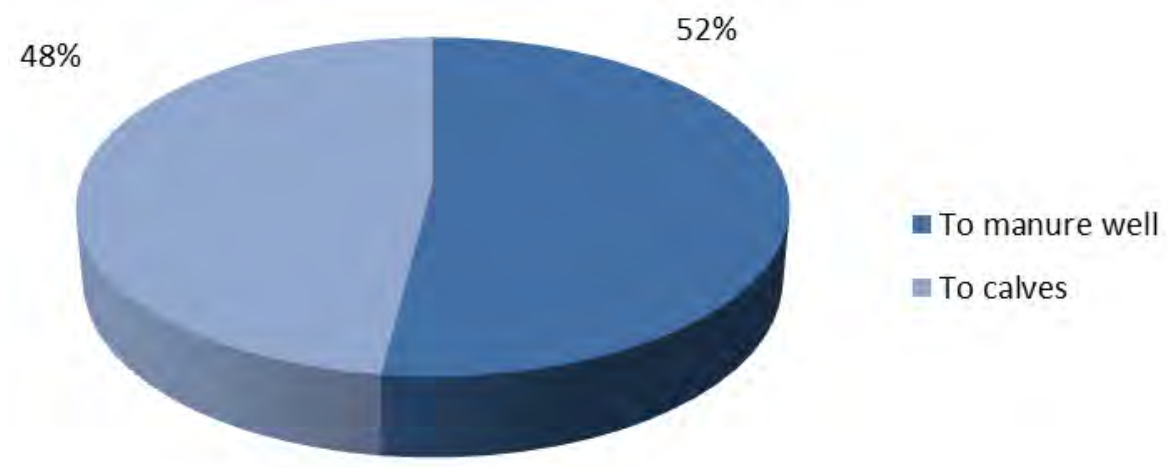

\subsection{Discussion}

\section{System boundaries}

The chosen system boundaries could be questioned. Regarding the whole chain from grass/concentrate to milk, the losses of feed resources would be a large waste factor on the dairy farm, which probably is even more important to reduce than the actual waste occurring in handling the milk. The losses of feed are about 5-10\% in the field, 5-20\% when storing the fodder and $5-10 \%$ when feeding the cows due to own estimations. These losses reduce milk production on the dairy farm and have major effect on the economy for the farmer. However, there is a need to differ between food waste and production losses, but this division is rather hard to determinate in the case of milk production.

Another aspect of the system boundaries is the production of meat from dairy cows. About 35-40 percent of the dairy cows are replaced every year. Meat produced from dairy cows and their offspring has less greenhouse gas emissions than meat produced in suckle cow systems (Cederberg et al 2012). However, there is today a tendency towards development of more specialised breeds of dairy cows which has less potential for meat production. Dual purpose breeds of dairy cows with potential for meat as well as milk production is in many aspects important for improving the overall efficiency of milk and beef meat production. Development of sex separation of sperms is another way to get a better meat production potential of bull calves from the dairy farms by selecting beef breeds for bull calves which will improve the growth rate for this category of animals (Jordbruksverket, 2010). 


\section{Uncertainty of the presented study}

According to the Swedish milk recording 2010 the average deliveries were 93 per cent of the recorded amount on the farms, 5 per cent was used on the farm and 2 per cent is unknown (Swedish Dairy Association, 2010). Seven per cent is not delivered to the dairy of the recorded milk. This is a significant larger amount than presented in the study of this paper. The weakness in the study presented is that the actual delivery to the dairy is rather unclear. If the total production of milk in the study is estimated only from milk recording, then the official statistics are more reliable. This would give larger waste figures, but the ratio would be about the same. The amount of milk waste should then be about twice as much as the amount in this study. However, the proportion of milk wasted in the primary production at the farms is still very small.

Another uncertainty in the results is related to how the farmer uses the penicillin treated milk. There could be a difference in how to handle penicillin treated milk between Agneta's interviewed farmers and farmers in other regions. In an on-going research project at SLU, 457 farmers were asked how they handle antibiotic treated milk. Figure 5 show that 55 percent of the farmers feed both treated milk and withdrawal milk to the calves. 25 percent of the farmers feed milk from the withdrawal period to calves and 20 percent of the farmers are not feeding any penicillin treated or withdrawal milk at all to the calves.

Figure 5. Distribution of how the 457 asked farmes are handling antibiotic treated milk (Duse et al, 2012)

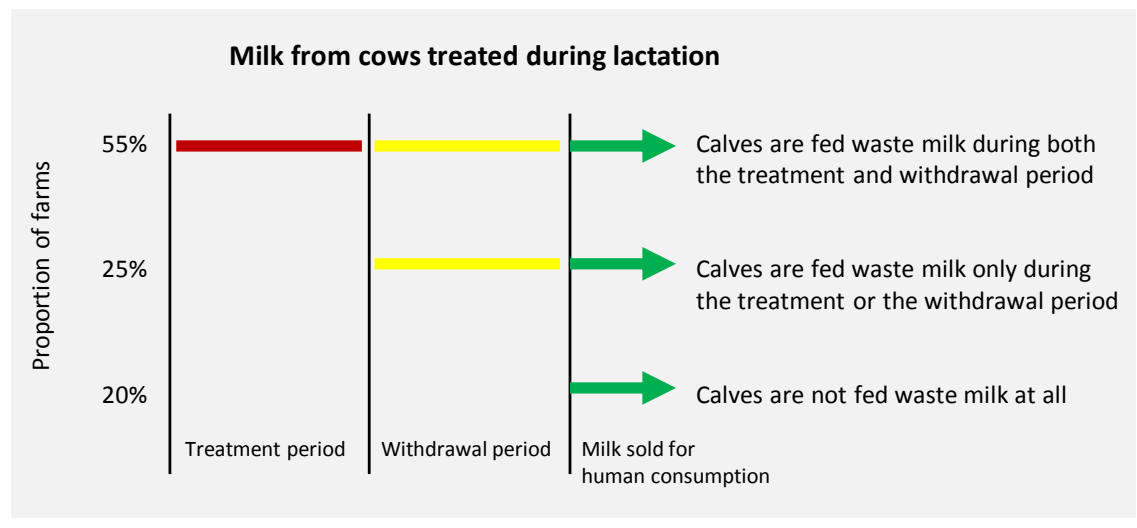

\subsection{Conclusions}

Of the 17 interviewed farmers the conclusion is that about 97 per cent of the milk produced at the farm is delivered to the dairy. 3 per cent of the milk is used to feed the calves their first period of life. Only 0.32 per cent of the milk can be defined as food waste and is thrown in the manure well on the farm. The main reason for milk waste in primary production is penicillin treatment due to mastitis. 
There is a big variation in how penicillin contaminated milk is handled. Feeding all milk from the withdrawal period to calves could be a potential for reducing milk waste, but this might be in conflict with medical aspects with problems concerning resistance for antibiotics in humans and animals.

\section{Further studies}

To get a more complete picture of the milk waste, more research on system boundaries and definition of milk waste is required. What are production losses and what is milk waste? There is also a need to find out the true proportion of milk delivered to the dairy in order to get a better estimation of the actual proportion that is thrown in the manure well. Furthermore, the SLU study of local differences in handling the milk and what the effects are on feeding antibiotic treated milk to calves is an important source for making recommendations for handling waste milk in the future.

\subsection{References}

Bergman A., 2012, "Människan, kalven eller gödselbrunnen? Mjölkens destination och fördelning- hos mjölkbonden," Examensarbete, Linnéuniversitetet institutionen för naturvetenskap.

Cederberg C, Hedenus F, Wirsenius S, Sonesson U., 2012. Trends in greenhouse gas emissions from consumption and production of animal food products - implications for long-term climate targets. Animal. 2013 Feb;7(2):330-40.

Jordbruksverket, 2010. MInskade växtnäringsförluster och växthusgasutsläpp till 2016. Rapport 2010:10.

Statistical data on production of milk from Swedish Board of Agriculture, 2012

Swedish Dairy Association 2010, Cattle statistics

Duse A. Emanuelson U. Ericsson Unnerstad H. Persson Y. Waller K. Bengtsson B., 2012, "Milk from cows treated with antimicrobials as feed for calves, a potential risk for selection of resistant bacteria," Poster material, SLU 


\section{Appendix Denmark "food waste" in primary production of pork}

Lisbeth Mogensen, John Hermansen, Anne Grete Kongsted, Department of Agroecology, Aarhus University, Denmark, 18 FebruaryOctober 2013.

\subsection{Introduction}

\subsubsection{Definition of "food waste" generated in the primary production of pork}

In the present study, "food waste" in the primary production of pork was defined as waste of animals, which was planned to be eaten by humans, if they were handled and used optimally through the whole chain from primary production to retail. Included in this "food waste" are animals that die due to illness and animals or parts of animals that are rejected at the slaughterhouse due to health risk for humans. By slaughtering and processing the live pig into meat, a wide range of by-products like for example blood are also generated. None of these is intended to be used as human food and is therefore not considered a food waste but a by-product.

In a study by FAO (20) they distinguish between "food losses" and "food waste". Where "food losses" refer to "a decrease in food quantity or quality in the early stages of the food supply chain, before the food products reach their final stage, reducing the amount of food suitable for human consumption. Following this definition, food losses are often related to post-harvest activities with poor system or infrastructural capacities." "Food waste" on the other hand refers to the discarding of food products that are fit for consumption or fit to proceed in the food supply chain. This mostly occurs at later stages of the food supply chain, such as retail and consumer households. Hence, the causes of food waste are often related to human behaviour (20)."

So, when we compare the two definitions, what the present study define as "food waste" in the primary production of pork is rather "food losses" according to the definition by FAO (20). When they add "food losses" and "food waste" it include "lost and wasted food throughout the whole food supply chain, referred to as food that could have been used for human consumption" which is equivalent to the definition of "food waste" in the present project. 


\subsection{System boundaries}

This study was conducted for Danish condition and includes the chain from pig farming to slaughtering where the pork leaves the slaughterhouse as half slaughter bodies. This means that a potential loss from processing of these half bodies into meat products (packed and ready to be sold) is allocated to the processing and distribution stage and therefore not included in this study.

The study by FAO (20) included all countries divided into three world regions with medium/high income and four regions with low income. Europe is one of the three world regions in medium/high income regions. In this appendix, the present study was compared with results from the European region in the FAO study.

In their study (20), the food supply chain was dived into five steps, where the following activities were included in food losses/waste:

- Agricultural production: For pork meat, losses refer to animal death during breeding.

- Postharvest handling and storage: For pork meat, losses refer to death during transport to slaughter and condemnation at slaughterhouse.

- Processing and packaging: For pork meat, losses refer to trimming spillage during slaughtering and additional industrial processing e.g. sausage production.

- Distribution: Include losses and waste in the market system, at e.g. supermarkets, retailers and wet markets.

- Consumption: Include losses and waste at the household level.

The present study was only related to primary production, and included the first two steps of the other study (20) with the same activities included in calculating the food losses/waste from these steps.

\subsection{Choice of method}

The data source in this study was existing statistic on productivity in private Danish pig herds based on recording of productivity in the individually herds as well as statistic from transport of pigs from farm to slaughterhouse. Data from slaughterhouse are from the major slaughterhouse in Denmark which is responsible for $78 \%$ of pig slaughtered.

In Gustavsson et al. (2013) (18), the production volumes were collected from FAO Statistical Yearbook 2009. The production volumes for Europe of pig meat were compiled by summarizing the volumes for the countries included in this region. Losses and waste of meat was reported in carcass weight (including bone). They used the waste percentages for rejection at slaughterhouse, mortality during transportation to slaughter 
and animal mortality during breeding and multiply with number of heads slaughtered in total. This is assumed to be number of finisher plus number of sows for slaughter.

\subsection{Method}

\subsubsection{Statistics}

Data from farm are based on the actual average output from farms of raw material for food production (here live weight of pigs) relative to the potential maximum output, if no dead animals were present in the system. At national level, numbers were adjusted for export of live pigs. Data in relation to transport of pigs include data on the percentage of dead animals during transport. Data from slaughterhouse include data on the actual output of pork relative to input of live pigs.

\subsubsection{Time period and geographical area}

The farm data were average data from 2011 from 664 sow herds (with 425.000 sows), 574 herds with weaners (with 9.4 million produced weaners of $31 \mathrm{~kg}$ ) and 746 herds with finishers (4.9 million produced) (1). These data represent $41 \%$ of the sows in Denmark in 2011. Further, data from 2009 and 2010 are shown as well.

\subsection{Results}

\subsubsection{Food waste in\%}

In Table 1 is given average numbers on "food waste" (here in form of dead animals and animals rejected at slaughterhouse) in primary productions of pork in Denmark. These numbers are calculated per sow with offspring. Dead animals are picked up by DAKA, a destruction plant, and this category 2 waste can serve as raw material in biogas production, as input in fertilizer production, or it is burned to generate heat thus saving coal or oil. When meat and bone meal are burned the ash can is used in cement production. Fat can also be burned but is mainly used for biodiesel production (17). 
Table 1. Data from primary production - average numbers per sow in Danish pig herds

\begin{tabular}{|c|c|c|c|c|c|c|}
\hline & Average number per sow ${ }^{3)}$ & \multicolumn{2}{|c|}{2011} & 2010 & 2009 & Ref \\
\hline \multirow[t]{2}{*}{ Litter/sow/year } & & 2.26 & & 2.26 & 2.25 & 1 \\
\hline & & $\begin{array}{r}\text { Per } \\
\text { litter }\end{array}$ & $\begin{array}{l}\text { Per } \\
\text { year }\end{array}$ & $\begin{array}{r}\text { Per } \\
\text { litter }\end{array}$ & $\begin{array}{r}\text { Per } \\
\text { litter }\end{array}$ & \\
\hline \multirow[t]{12}{*}{ Piglets } & Total number of piglets born, $\mathrm{N}^{9}$ & 16.6 & 37.5 & 16.3 & 16.1 & 1 \\
\hline & Still born, N & 1.8 & 4.1 & 1.8 & 1.9 & 1 \\
\hline & $\%$ of total born & 10.8 & - & 11.0 & 11.8 & 1 \\
\hline & Weight, $\mathrm{kg} / \mathrm{pig}{ }^{1}$ ) & 1.5 & - & - & - & 2 \\
\hline & Live born, $\mathrm{N}$ & 14.8 & 33.4 & 14.5 & 14.2 & 1 \\
\hline & Dead before weaning, $\mathrm{N}$ & 2.1 & 4.7 & 2.1 & 2.0 & 1 \\
\hline & $\%$ of total born & 13.9 & - & 14.2 & 14.0 & 1 \\
\hline & Weight, $\mathrm{kg} / \mathrm{pig}^{2)}$ & 1.5 & - & - & - & - \\
\hline & Total number of dead piglets, $\mathrm{N}$ & 3.9 & 8.8 & 3.9 & 3.9 & 1 \\
\hline & $\%$ of total born & 23.0 & - & 23.6 & 24.2 & 1 \\
\hline & Weaned piglets, $\mathrm{N}$ & 12.7 & 28.8 & 12.4 & 12.2 & 1 \\
\hline & Weight of 1 weaned piglet, $\mathrm{kg}$ & 7.1 & & 7.2 & 7.4 & 1 \\
\hline Weaners & Dead before $30 \mathrm{~kg}, \mathrm{~N}$ & 0.37 & 0.83 & 0.35 & 0.32 & - \\
\hline \multirow{3}{*}{ (7.1- 31.7kg) } & $\%$ of weaned & 2.9 & - & 2.8 & 2.6 & 1 \\
\hline & Weight, $\mathrm{kg} / \mathrm{pig}^{4)}$ & 7.1 & - & 7.2 & 7.4 & - \\
\hline & Number of weaners prod., $\mathrm{N}$ & 12.33 & 27.9 & 12.05 & 11.88 & 1 \\
\hline \multirow{4}{*}{$\begin{array}{l}\text { Finishers } \\
(31.7-106.9 \mathrm{~kg})\end{array}$} & Dead and rejected pigs, $\mathrm{N}^{8)}$ & 0.46 & 1.03 & 0.48 & 0.49 & - \\
\hline & $\%$ of produced $30 \mathrm{kgs}^{7)}$ & 3.7 & - & 4.0 & 4.1 & 1 \\
\hline & Weight, $\mathrm{kg} / \mathrm{pig}{ }^{5)}$ & 69.3 & - & - & - & - \\
\hline & Number of finisher produced, $\mathrm{N}$ & 11.87 & 26.8 & 11.57 & 11.39 & - \\
\hline \multirow[t]{2}{*}{ Sows } & Dead sows,\% per sow per year & 13.7 & - & 14.4 & $15^{6)}$ & $3+4$ \\
\hline & $\begin{array}{l}\text { Number of replaced sows slaugh- } \\
\text { tered, } \mathrm{N}\end{array}$ & 0.24 & 0.54 & 0.24 & 0.24 & 1 \\
\hline
\end{tabular}

\footnotetext{
1. These piglets are assumed to have same weight as live born piglets. Weight of live born piglets are given by Thorup (2010) (2).

2. These piglets typical die short time after they are born (10) - therefore average birth weight of live born piglets is used.

3. All numbers are calculated per sow per litter $(2011,2010,2009)$ and per sow per year (2011).

4. These pigs are assumed to die short time after they are inserted in the weaners stable - therefore average weight of weaned piglets is used.

5. The time, where finishers die is assumed to be uniform distributed during the period. Therefore, an average weight (from 31.7 to $106.9 \mathrm{~kg}$ ) of $69.3 \mathrm{~kg}$ was used.

6. Data from 2008.

7. Out of this, the share of finishers rejected at slaughterhouse is $0.2 \%$ (table 2 ) and the share of dead finishers is $3.5 \%$.

8. This number include both finishers that die at the farm and finishers that are rejected at the slaughterhouse.

${ }^{9}$ Including both live and dead born piglets.
} 
In Table 2 are shown the number of pigs that die during transport from farm to slaughterhouse and the number of pigs that are rejected at slaughterhouse.

Table 2. Mortality rate during transport and pigs rejected at slaughterhouse

\begin{tabular}{lccc}
\hline & Finishers & Sows & Ref \\
\hline Dead during transport,\% & 0.01 & 0.07 & 7 \\
Rejected at slaughterhouse,\% & 0.18 & 1.21 & 8 \\
\hline
\end{tabular}

To calculate the total "food waste" in primary production of pork in Denmark in 2011, the average numbers for "food waste" given per sow per year in table 1 are set together with statistic on total number of sows in Denmark, taking into account that some pigs are exported (6).

Table 3. Total "food waste" (dead pigs and pigs rejected at slaughterhouse) in Denmark in primary production of pork in 2011

\begin{tabular}{|c|c|c|}
\hline & & Reference \\
\hline \multicolumn{3}{|l|}{ Piglet production } \\
\hline Total number of sows in Denmark ${ }^{1)}$ & $1,034,000$ & 5 \\
\hline Total number of piglets born ( 37.5 per sow/year) & $38,775,000$ & Table 1 \\
\hline Total numbers of dead piglets before weaning $(23,0 \%)^{2)}$ & $8,918,250$ & Table 1 \\
\hline Total weight of dead piglets $(1,5 \mathrm{~kg}) 2), 1000$ ton & 13.4 & Table 1 \\
\hline Total number of piglets weaned ( 28,8 per sow/year) & $29,779,200$ & Table 1 \\
\hline Number of piglets exported ${ }^{3)}$ & 406,942 & 6 \\
\hline Total number of piglets left for weaner production in $\mathrm{Dk}^{10)}$ & $29,372,258$ & \\
\hline \multicolumn{3}{|l|}{ Weaner production $(7.1-31.7 \mathrm{~kg})$} \\
\hline Total number of piglets for weaner production in Denmark & $29,372,258$ & \\
\hline Total numbers of dead weaners $(2.9 \%)^{4)}$ & 851,795 & Table 1 \\
\hline Total weight of dead weaners $(7.1 \mathrm{~kg}), 1000$ ton & 6.0 & \\
\hline Total number of $30 \mathrm{kgs}$ pigs produced in Denmark 4) & $28,520,463$ & \\
\hline Number of $30 \mathrm{~kg}$ pigs exported ${ }^{5)}$ & $7,632,169$ & 6 \\
\hline Total number of weaners left for finisher production in Denmark & $20,888,294$ & \\
\hline \multicolumn{3}{|l|}{ Finisher production $(31.7-107 \mathrm{~kg})$} \\
\hline Total number of pigs for finisher production in Denmark & $20,888,294$ & \\
\hline Total numbers of dead finisher $(3.5 \%)^{6)}$ & 731,090 & Table 1 \\
\hline Weight of dead finishers (69.3 kg), 1000 ton & 50.7 & \\
\hline Total number of $107 \mathrm{~kg}$ finishers produced in Denmark & $20,157,204$ & \\
\hline Number of finishers exported & 382,373 & 6 \\
\hline Total number of finishers transported to slaughtering in Denmark & $19,774,830$ & \\
\hline Total numbers of dead finisher during transport $(0.01 \%)^{4)}$ & 1977 & Table 2 \\
\hline Weight of dead pigs $(107 \mathrm{~kg}), 1000$ ton & 0.2 & \\
\hline Total number of finishers ready for slaughtering in Denmark ${ }^{8)}$ & $19,772,854$ & \\
\hline Number of finishers rejected at slaughter house $(0.2 \%)$ & 35,196 & Table 2 \\
\hline Weight of rejected pigs $(107 \mathrm{~kg}), 1000$ ton & 3.8 & \\
\hline Total number of finishers used for meat production & $19,737,658$ & \\
\hline Total "meat production" from finishers, 1000 ton LW (107 kg) & 2111.9 & \\
\hline \multicolumn{3}{|l|}{ Sow production } \\
\hline Total number of sows in Denmark ${ }^{1)}$ & $1,034,000$ & 5 \\
\hline Total number of dead sows (13.7\%) & 141,658 & Table 1 \\
\hline Weight of dead sows (205 kg), 1000 ton & 29.0 & \\
\hline Number of replacement sows $(40.3 \%)^{7)}$ & 416,847 & \\
\hline Number of replacement sows exported & 118,022 & 6 \\
\hline Number of replacement sows sent to slaughter houses in DK & 298,825 & \\
\hline Numbers of sows that die during transport to sl. house $(0.07 \%)^{4)}$ & 209 & Table 2 \\
\hline
\end{tabular}




\begin{tabular}{|c|c|c|}
\hline & & Reference \\
\hline Total weight of dead sows - from transport (205 kg), 1000 ton & 0.04 & \\
\hline Number of sows slaughtered in Denmark ${ }^{8)}$ & 298,616 & \\
\hline Number of sows rejected at slaughter house (1.2\%) & 3604 & Table 2 \\
\hline Weight of rejected sows (205 kg), 1000 ton & 0.8 & \\
\hline Total number of sows used for meat & 295,012 & \\
\hline Total "meat production" from sows (205 kg), 1000 ton live weight & 60.5 & \\
\hline \multicolumn{3}{|l|}{ Total "food waste" in primary pork production in 2011} \\
\hline Total number of dead and rejected pigs, million pigs ${ }^{12)}$ & 10.7 & \\
\hline Total weight of dead and rejected pigs, live weight 1000 ton $^{11)}$ & 103.9 & \\
\hline Total weight of waste per sow including all offspring, kg /year & 101 & \\
\hline Total DK pork production, 1000 ton live weight ${ }^{9)}$ & 2172 & \\
\hline Total waste in $\%$ of total (live weight) pork production & 4.8 & \\
\hline
\end{tabular}

1. Pig counting in Denmark per 1. of April 2011: 785,000 pregnant sows $+211,000$ lactating sows + 38,000 dry sows

2. Included is also stillborn piglets

3. According to Danish Statistic (2011): 406,942 pigs between 0-15 kg LW are exported. In the present study, these pigs are assumed exported right after weaning at $7.2 \mathrm{~kg}$ live weight

4. Exclusive exported pigs/sows

5. According to Danish Statistic (2011): 7,632,169 pigs between 15-50 kg LW are exported. In the present study, these pigs are assumed exported at $30 \mathrm{~kg} \mathrm{LW}$.

6. The numbers for percent dead finishers in Table 1 (3.7\%) include both finishers rejected at slaughterhouse $(0.2 \%)$, and finishers that dies (3.5\%).

${ }^{7}$ Replacement rate per sow per year is calculated as '\% 1 .lactation sows' * 'number of litter $/$ sow $/$ year' $=(23.9 \% * 2.26)=54.0 \%$. This is also the sum of dead sows $(13.7 \%)$ and sows sent for slaughtering $(40.3 \%)$

${ }^{8 .}$ The calculated numbers of sows and finishers slaughtered in Denmark of 20,071,470 (in Table 3 ) is $4 \%$ lower than the number given by Danish Statistic (9) for 2011: 20,925,925 finishers + sows slaughtered.

9. Finishers: $19,737,658 * 107 \mathrm{~kg}+$ slaughter sows: $295,012 * 205 \mathrm{~kg} / \mathrm{sow}$

10. Weaned piglet - piglet exported right after weaning

11. Sum of the weight of dead piglets, dead weaners, dead finishers and dead sows from farms, and the weight of pigs that die during transport to slaughterhouse and weight of pigs that are rejected at the slaughterhouse (sum of numbers with bold).

12. Number of dead piglets, dead weaners, dead finishers and dead sows from farms, and number of pigs that die during transport to slaughterhouse and pigs that are rejected at the slaughterhouse.

In the study by Gustavsson et al. (18), they used the same mortality rate during breeding for all European countries. They assumed an average $2.5 \%$ mortality rate for all types of pig in Europe based on a $2.5 \%$ mortality rate at Swedish farms for fattened pigs (19). This mortality rates are given as waste percentages according to number of heads slaughtered (we interpret this as $2.5 \%$ mortality among sows and $2.5 \%$ mortality among finishers, whereas mortality among piglets and weaners was not included). They used the same carcass weight of $88 \mathrm{~kg} / \mathrm{head}$ for all dead pigs (correspond to $115 \mathrm{~kg}$ live weight). Mortality during transport to slaughter and rejection at slaughterhouse were based on assumptions: $0.11 \%$ mortality rate for pigs transported to slaughter in Europe and $0.12 \%$ of pigs rejected at slaughter in Europe, respectively.

In Table 4 are shown data for the process from the slaughterhouse, where live finishers are turned into pork and by-products. Data from Danish Crown (15). 


\begin{tabular}{|c|c|}
\hline 1 finisher, living pig, $\mathrm{kg}^{1)}$ & 103.6 \\
\hline \multicolumn{2}{|l|}{ Output: } \\
\hline Pork, kg/pig ${ }^{2)}$ & 81 \\
\hline Materials for biogas, $\mathrm{kg} / \mathrm{pig}^{3)}$ & 5.6 \\
\hline Category $3, \mathrm{~kg} / \mathrm{pig}{ }^{4)}$ & 9.8 \\
\hline Category $2, \mathrm{~kg} / \mathrm{pig}^{5)}$ & 2.5 \\
\hline Blood, $\mathrm{kg} / \mathrm{pig}{ }^{6)}$ & 3.33 \\
\hline
\end{tabular}

1. Weight of one living pigs is based upon empirically data. The weight of a pig after slaughtering is multiplied with a factor to compensate for entrails, loss of blood etc.

2. Average weight of a slaughtered pig is calculated from all slaughtering in 2009/10.

3. Includes contents of casings and stomach, sawdust from the transport to the slaughterhouse and slurry from the staples at the slaughterhouse. The material is reused for production of heat and electricity in biogas plants and afterwards used as fertilizer in agriculture.

4. All category 3 material from the slaughterhouses is reused as pet food. The amount of Category 3

is based upon empirically data from measurements.

5. All category 2 material from the slaughterhouses is reused. The fat is melted and converted to biodiesel. The rest (bones, meat etc.) is either used as fertilizer or rendered.

6. All blood from the slaughterhouses is reused. Blood taken out sterile, is used for ingredients in human food. All other blood from the bleeding area is converted into pet food. The amount is based upon empirical data.

\subsection{Reasons behind the "food waste"}

Dead piglets: At farm level it is often difficult to know if a dead piglet was stillborn or died just after being born. Therefore the distribution between "stillborn" and "dead before weaning" (Table 1) might be wrong, whereas the total number of dead piglets $(23 \%)$ is quite sure. By postmortem examination in 10 herds (12), the following reason for dying was found:

- $22.6 \%$ stillborn (10)

- $24.0 \%$ dead due to crushing or trauma (12)

- $24.0 \%$ due to malnutrition (12)

- $13.0 \%$ due to illness like blood poisoning, arthritis, diarrhea (12)

- $3.0 \%$ due to injury at castration (12)

- $13.4 \%$ others or not found

Dead weaners: Based on post-mortem examination in 3 herds, the following reasons were found (13):

- $25.5 \%$ due to gastrointestinal disorders

- $22.7 \%$ general infection by bacteria

- $17.6 \%$ pneumonia

- $14.3 \%$ arthritis

- $8.9 \%$ otitis media

- $11 \%$ others or not found 
Dead finishers: Based on post-mortem examination in 3 herds, the following reasons were found (13):

- $23.5 \%$ pneumonia

- $20.2 \%$ arthritis

- $19.3 \%$ general infection by bacteria

- $19.3 \%$ several different diseases

- $10.9 \%$ otitis media

- $6.8 \%$ others or not found

Dead sows: Based on post-mortem examination in 2001-2003 in 10 herds, the following reasons were found (14):

- $52.8 \%$ euthanized:

* $37 \%$ due to locomotors disorders (20\% joint disorder, $9 \%$ fracture, $8 \%$ ostitis)

* $6 \%$ due to infection

* $5 \%$ due to reproductive disorders

* $4 \%$ others or not found

- $47.2 \%$ sudden death:

* $11 \%$ due to organ torsion

* $11 \%$ related to reproduction (retained fetus, metritis, and unfortunate obstetrical assistance)

* $8 \%$ due to gastrointestinal disorders

$* 5 \%$ related to heart

* $12 \%$ others or not found

Dead during transport: Due to strict regulation on transport and short duration hereof $(<3$ hours for $95 \%$ of the pigs) these numbers are among the lowest in the world (7).

Rejected at slaughterhouse: The major part is made up of pigs that by the veterinary control are detected to have some kind of illness, and only healthy animals can be used as human food. A minor part is made up of pigs that are euthanized immediately after they arrive due to injury from the transport.

\subsubsection{Measures to reduce waste}

In this case reduced waste means reduced mortality in the pig herds. In the Danish pig sector the aim is to reduce pig mortality by $20 \%$ before 2020 (16) both from a welfare and an economic point of view. The aim is planned to be reached by using the following initiatives:

- Breeding for stronger and more surviving piglets (increased\% live born piglets and increased chances for surviving the first critical day) 
- Improving maternal traits and increasing milk production by the sow, to reach 14 weaned piglets/litter.

- Improved environment in farrowing pens and other stables.

- Management strategies for handling large litter sizes.

- Barriers for transmission of diseases between groups.

- Using handbooks to secure correct work routines in stable.

- Breeding for improved longevity and improved leg condition among sows. (16).

\subsection{Discussion}

We think the used method was appropriate for the purpose. Due to representative statistical data of high quality it was possible to estimate an overview over dead and rejected animals in the chain from born piglet to slaughtered pig, both as total numbers and as amount in kg live pig. The farm data used for productivity and mortality in farms represent $41 \%$ of production in Denmark in 2011. And by using the counted number of sows as a starting point and calculate the production of piglet over weaners to finisher taking into account pigs that die or are exported, we came up with a calculated number of pigs slaughtered in Denmark that only differ $4 \%$ from the number given by the Danish Statistic. Thereby, we find the calculated results for "food waste" reliable.

If we compare the results in the present study with the results from Gustavsson et al. (18) representing Europe, the waste percentages for rejection at slaughterhouse and mortality during transportation to slaughter differ $(0.12 \%$ versus $0.18 \%$ finishers $/ 1.21 \%$ sows rejected in the present study; and similar $0.11 \%$ of the pigs versus $0,01 \%$ finishers $/ 0.07 \%$ sows die during transport in the present study). However, these two categories of food waste were only responsible for $5 \%$ of the total food waste (live weight of dead and rejected pigs) in the present study.

Gustavsson et al. (18) concluded that out of the total pork production in Europe in 2007 (26,750,000 ton carcass weight (CW)), 2.8\% end as food losses; 32000 ton CW were rejected at slaughterhouse, 29,000 ton CW died during transport to slaughterhouse and 687,000 ton CW die during breeding. In the present study the total food waste in primary production correspond to $4.8 \%$ of total (live weight) pork production.

The fact that in the present study, losses were calculated as live weight whereas Gustavsson et al. (18) calculate in carcass weight could not explain the difference, since this is only a multiplication factor. The main reason for the difference might be the way food losses during breeding were calculated. In the present study, we looked at mortality at all stages during pork production: piglets, weaners, finishers and sows whereas Gustavsson et al. (18) only included mortality among the end product, the slaughtered animals (finishers and sows). In the present study, the weight of dead piglet and weaners are not negligible as they 
are responsible for $19 \%$ of the total weight of food losses in the form of dead and rejected pigs.

Besides that, Gustavsson et al. (18) used the same carcass weight of $88 \mathrm{~kg} / \mathrm{head}$ for both dead finishers and dead sows (correspond to 115 $\mathrm{kg}$ live weight). This means an underestimation of $\mathrm{kg}$ food waste per dead sows (205 kg LW in the present study) and an overestimation of kg food waste per dead finisher (69.3 kg LW in the present study). However, this mainly outweight each other.

Last, but not least, in the study by Gustavsson et al. (18), they used $2.5 \%$ mortality among finishers where we used the actual 3.5\% found under Danish condition and similar they (18) used 2.5\% mortality among sows where we used the actual $13.7 \%$ found under Danish condition. If we had used the mortality rates from their study (18), food losses from these two groups of pig would be halved. In conclusion, this is the main explanation for the lower $(2.8 \%)$ overall food losses in pork production found by Gustavsson et al. (18) compared with a total food waste of $4.8 \%$ found in the present study.

\subsection{Conclusion}

In the present study, total "food waste" in Danish primary production of pork in form of dead and rejected animals in the chain from birth of the piglets to the finishers (and replacement sows) were slaughtered was calculated to make up 105,000 ton live weight (LW) of pigs. Per sow that means $101 \mathrm{~kg} \mathrm{LW}$ wasted per year or $5 \%$ of the total production of pork (live weight). In numbers of animals the highest contribution came from dead piglets, nearly 9 million per year. However, due to low weight of each piglet this waste only contributes $13 \%$ to the total waste in $\mathrm{kg}$. The bulk of the "waste" measured in kg was dead finisher, which was responsible for $49 \%$ of the total "food waste" in primary production of pork. From a waste point of view, a total "food waste" in Danish primary production of pork of $5 \%$ of the total production of pork is relatively low, but from welfare and an economic point of view it is important to reduce mortality. The aim of the Danish pig sector is to reduce mortality by $20 \%$ before 2020 . 


\subsection{References}

(1) Vinter, J. 2012. Landgennemsnit for produktivitet I svineproduktionen 2011. Notat nr. 1212. Videncenter for Svineproduktion. $15 \mathrm{pp}$.

(2) Thorup, F. 2010. Fødselsvægt. Videncenter for Svineproduktion. http://vsp.lf.dk/Viden/Reproduktion/Faring_diegivning/Fodselsvaegt.aspx?full=1

(3) Anonymes. 2011. Reduktion af dødeligheden med 20 pct. Videncenter for Svineproduktion. $2 \mathrm{pp}$

http://vsp.lf.dk/Aktuelt/Velfaerd/Reduktion\%20af\%20dodeligheden\%20med\%20 20\%20pct.aspx

(4) Anonymes. 2012. Landbrugsavisen 21. maj 2012.

(5) Anonymous. 2012. Danmarks Statistiks opgørelse af svinebestanden den 1. juli 2012. 1 pp.

http://www.lf.dk/ /media/lf/Tal\%20og\%20analyser/Aktuelle\%20statistikker/a ktuelle\%20svin/bestand/Bestand\%20jul12.ashx

(6) Landbrug og Fødevarer. Eksporten af levende svin. Data for 2011 www.lf.dk/Tal-og_analyser

(7) Videncenter for Svineproduktion. 2011. Svineproducenter i verdensklasse. http://vsp.lf.dk/Aktuelt/Nyheder/2011/11/10112011_Svineproducenter\%20i\%2 0Verdensklasse.aspx

(8) Danish Crown. Personal communication. Data from October 2011 - September 2012.

(9) Landbrug og Fødevarer. 2012a. Statistik 2011, Svinekød. Viden - Vækst - Balance. http://www.lf.dk/Aktuelt/Publikationer/ /media/lf/ Tal\%20og\%20analyser/Aarsstatistikker/Statistik\%20svin/2011/072 2012_A5\%20Statistik\%20DK2011.ashx

(10) Pedersen et al. 2010. Neonatal piglet traits of importance for survival in crates and indoor pens in two genetic groups differing in genetic survival rate. J. Anim. Sci.

(11) Edwards et al. 1994. An analysis of the causes of piglet mortality in a breeding herd kept outdoors. Veterinary Record. 135, 324-327.

(12) Svensmark et al. 2010. Dødsårsager hos pattegrise. Internt notat VSP - L\&F. 3 pp.

(13) Haug. 2002. Dødsårsager hos svin. VETINFO nr 0222. Videncenter for Svineproduktion. 3 pp.

(14) Vestergaard. 2004. Afgangsårsager hos søer - samt obduktionsfund hos aflivede og selvdøde søer. Meddelelse nr. 656. Videncenter for Svineproduktion. 17 pp.

(15) Data from Danish crown published in Nguyen, T.L., Hermansen, J.E., Mogensen, L. 2011. Environmental assessment of Danish pork. Intern rapport nr. 103. Det Jordbrugsvidenskabelige Fakultet, Århus Universitet. 31 pp. www.agrsci.au.dk

(16) Videncenter for Svineproduktion. 2011. Reduktion af dødeligheden med 20\%. http://vsp.lf.dk/Aktuelt/Velfaerd/Reduktion\%20af\%20dodeligheden $\% 20$ med $\% 2$ 020\%20pct.aspx

(17) DAKA. 2012. www.dakabio-industries.dk

(18) Gustavsson J, Cederberg C, Sonesson U, og Emanuelsson A. The Metodology of the FAO study: "Global Food Losses and Fooed Waste- extent, causes and prevention"-FAO 2011. By SIK - The Swedish Institute for Food and Biotechnology., January 2013.

(19) Svenska_Pig 2010. www.svenskapig.se

(20) FAO. (2011). Global Food Losses and Food Waste - extent, causes and prevention. Rome: Food and Agriculture Organization of the United Nations. 
Nordiska ministerrådet

Ved Stranden 18

DK-1061 København K

www.norden.org

\title{
Kartläggning av matsvinnet i primärproduktionen
}

\begin{abstract}
Mat slängs i alla delar av livsmedelskedjan. Det finns statistik på hur mycket som kastas i flera led av kedjan men för primärproduktionen, alltså jordbrukarnas verksamhet, saknas tillförlitliga siffror på hur stort svinnet är. I ett projekt med representanter från Danmark, Finland, Norge och Sverige har vi försökt kartlägga svinnet i fem vanliga produktgrupper: Mjölk, griskött, morötter, lök och potatis. Resultaten visar att en stor mängd mat går förlorad redan i primärproduktionen. Svinnet av mjölk och griskött har störst konsekvenser för producenternas ekonomi, mängden tillgänglig odlingsmark och klimatet även om svinnet i produktionen procentuellt sett är högre för morötter, lök och potatis. Konsumenternas krav kan ge upphov till svinn även $\mathrm{i}$ primärproduktionen särskilt för frukt och grönsaker.
\end{abstract}

